Review

\title{
Molecularly Imprinted Polymers with Stimuli-Responsive Affinity: Progress and Perspectives
}

\author{
Wei Chen ${ }^{1,2, \dagger}$, Yue Ma ${ }^{3, \dagger}$, Jianmin Pan ${ }^{3, *}$, Zihui Meng ${ }^{1}$, Guoqing Pan ${ }^{2,4, *}$ and \\ Börje Sellergren ${ }^{4, *}$ \\ ${ }^{1}$ School of Chemical Engineering \& the Environment, Beijing Institute of Technology, \\ Beijing 100081, China; E-Mails: chenwei30012@163.com (W.C.); mengzihui@bit.edu (Z.M.) \\ ${ }^{2}$ Orthopaedic Institute, Soochow University, 708 Renmin Road, Suzhou 215007, Jiangsu, China \\ ${ }^{3}$ School of Chemistry and Chemical Engineering, Jiangsu University, 301 Xuefu Road, \\ Zhenjiang 212013, Jiangsu, China; E-Mail: yamma1113@126.com \\ ${ }^{4}$ Department of Biomedical Sciences, Faculty of Health and Society, Malmö University, \\ SE 20506 Malmö, Sweden
}

$\dagger$ These authors contributed equally to this work.

* Authors to whom correspondence should be addressed; E-Mails: jsdxpjm@126.com (J.P.); yueer@suda.edu.cn or tepid2010@gmail.com (G.P.); borje.sellergren@mah.se (B.S.); Tel.: +86-511-8879-1800 (J.P.); +86-512-6778-1420 (G.P.); +46-40-6657-810 (B.S.); Fax: +86-512-6778-1420 (G.P.).

Academic Editor: Michael K. C. Tam

Received: 5 August 2015 / Accepted: 24 August 2015 / Published: 8 September 2015

\begin{abstract}
Intelligent stimuli-responsive molecularly imprinted polymers (SR-MIPs) have attracted considerable research interest in recent years due to the potential applications in drug delivery, biotechnology and separation sciences. This review comprehensively summarizes various SR-MIPs, including the design and applications of thermo-responsive MIPs, pH-responsive MIPs, photo-responsive MIPs, biomolecule-responsive MIPs and ion-responsive MIPs. Besides the development of current SR-MIPs, the advantages as well as the disadvantages of current SR-MIPs were also displayed from different angles, especially preparation methods and application fields. We believe this review will be helpful to guide the design, development and application of SR-MIPs.
\end{abstract}


Keywords: molecularly imprinted polymers; thermo-responsive; pH-responsive; photo-responsive; biomolecule-responsive; ion-responsive

\section{Introduction}

Inspired by the mechanism of enzyme catalysis and antibody formation, researchers have been committed to exploring similar synthetic approaches with the purpose of obtaining tailored binding materials by chemical means [1]. To date, molecular imprinting has proven to be the most efficient and versatile technique for incorporating specific molecular recognition sites into polymers leading to polymeric artificial receptors [2-8]. The essential molecular imprinting process involves the self-assembly of a template molecule and a functional monomer via either non-covalent interactions (such as hydrogen bonding, van der Waals forces, ionic interactions, hydrophobic interactions or metal coordination interactions, etc.) or via reversible covalent bonds, the resulting complexes subsequently being copolymerized with a suitable cross-linker [9]. After removal of the templates from the obtained cross-linked polymer network, binding cavities complementary in shape, size and functionality to the template are formed [10] (Figure 1). The resultant molecularly imprinted polymers (MIPs) have found use in a wide range of applications encompassing the fields of separation processes (chromatography, capillary electrophoresis, solid phase extraction, and membrane separation), immunoassays [11], antibody mimics [12], artificial enzymes [13], sensors [14], catalysis [15], organic synthesis, drug delivery [16] and drug development [17]. This versatility stems from their favorable properties, e.g., mechanical, thermal, chemical stability, ease of preparation, low cost, and especially high affinity.

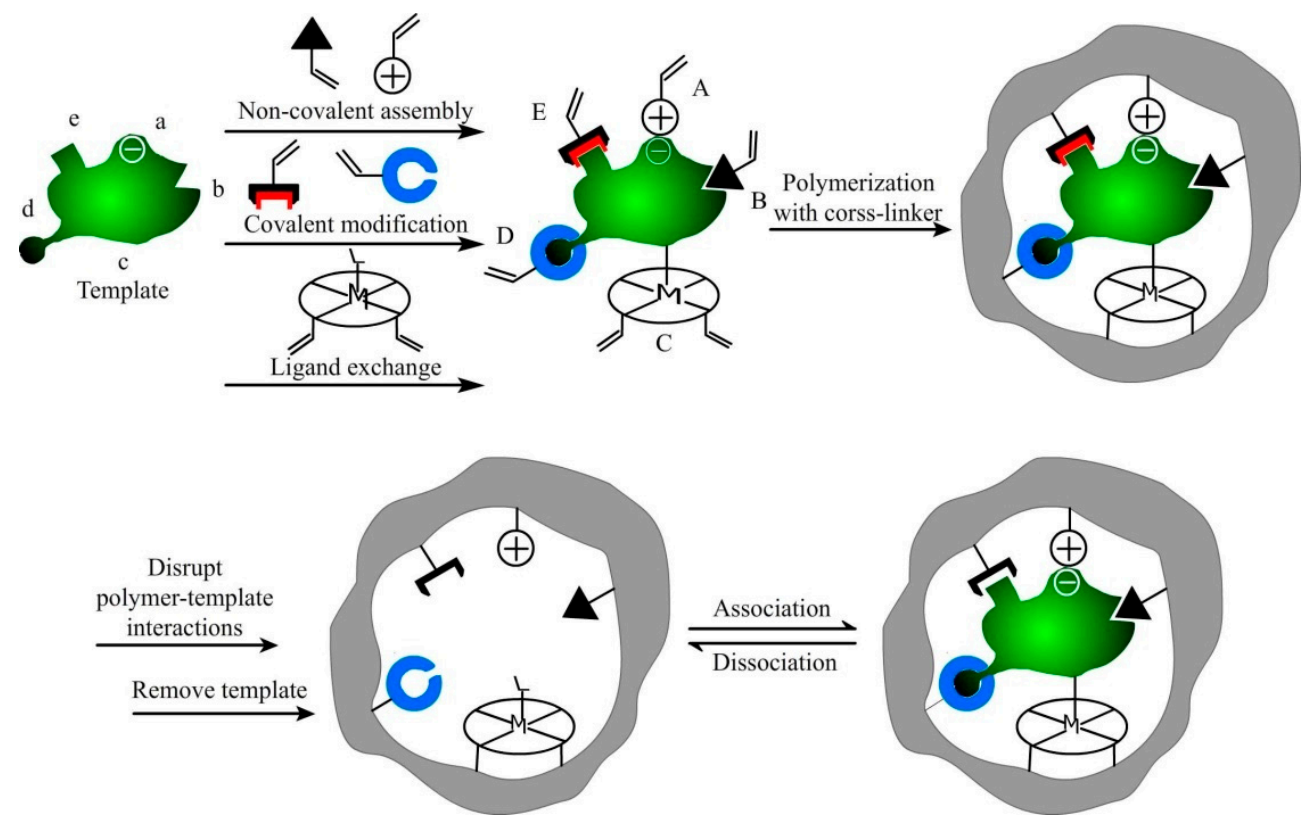

Figure 1. Highly schematic representation of the molecular imprinting process. Reprinted with permission from Reference 3. Copyright 2014, Wiley.

In spite of the tremendous progress that has been made in the molecular imprinting field, many challenges (e.g., applications in biology) remain to be addressed, especially in the design of advanced 
MIP materials mimicking the biological receptors [18,19]. It is known that one of the most fascinating characteristics of the natural receptors is their high responsiveness towards external stimuli (e.g., the temperature, $\mathrm{pH}$, etc.). Therefore, in order to find the perfect consistency between the synthetic receptor and the natural one, stimuli-responsive (also called "stimuli-sensitive" or "smart") MIPs have attracted considerable research interest in recent years [20-23].

The effective and general methodology to design stimuli-responsive MIPs is the combination of stimuli-responsive materials and the molecular imprinting technique, which endow the MIPs with the ability to respond to external stimuli while modulating their affinity for the target molecules and providing a switchable capacity of the binding or releasing processes. Currently, a variety of intelligent MIPs have been prepared which respond to specific stimuli such as changes in temperature [24], $\mathrm{pH}$ [25], incident light [26], ionic strength [27], or even the presence of a specific molecule [6,28]. Puoci et al. have reviewed work in the field until 2008 with special focus on a series of stimuli-responsive MIPs and their applications in drug delivery systems (DDS) [29]. The article gave a systematic classification of stimuli-responsive MIPs in DDS. Moreover, the development of stimuli-responsive MIPs, such as their applications and methodologies, has grown rapidly in recent years [6,30-32]. Therefore, in this review, we provide an overview of different responsive MIPs developed until now (Table 1), especially their synthetic methods, material formats and applications, furthermore, considering the challenges presently encountered and some feasible resolutions. By means of the points raised in this article, we would like to provide some assistance for further development of preparation methodologies and the expansion of some potential applications in the field of stimuli-responsive MIPs.

Table 1. Overview of different responsive MIPs.

\begin{tabular}{|c|c|c|c|c|}
\hline Stimulus & Template & Monomer and cross-linker & Form of MIPs & Reference \\
\hline \multirow{25}{*}{ Thermo-responsive } & \multirow{3}{*}{ Lysozyme } & NIPAAm, AA, DMAPMA, MBAAm & Particle & {$[24]$} \\
\hline & & NIPAm, MAA, AAm, MBAA & Core-shell & {$[33,34]$} \\
\hline & & NIPAm, VBIDA, AAm, MBAA & Bulk & [35] \\
\hline & 2,4-D & NIPAAm, 4-VP, EGDMA & Particle & [36] \\
\hline & RGDS Peptide & NIPAAm, AAm, DMAPMA, MBAA & Hydrogel layers & [37] \\
\hline & Propranolol & NIPAAm, MPABA, EGDMA & Particle with brush & [38] \\
\hline & Curcuminoids & NIPAAm, 4-VP, EGDMA & Core-shell & [39] \\
\hline & Sulfamethazine & NIPAm, AAm, EGDMA & Core-shell & {$[40]$} \\
\hline & CFX & NIPAm, MAA, EGDMA & Core-shell & [41] \\
\hline & 2,4,5-Trichlorophenol & NIPAm, MAA, EGDMA & Core-shell & [42] \\
\hline & 4-Amino pyridine & NIPAm, MAA, EGDMA & Hydrogel & [43] \\
\hline & $\mathrm{Cu}(\mathrm{II})$ ion & NIPAm, VBEDA,MBAA & Hydrogel & [44] \\
\hline & DBTS & Chitosan, Glutaraldehyde & hydrogel & [45] \\
\hline & Cisplatin & HEMA, MAA, MBAA & Hydrogels & [46] \\
\hline & \multirow{3}{*}{ BSA } & TBA, AAm, MA, MBAA & Hydrogels & [47] \\
\hline & & AMPS, NIPAm, AAm & Hydrogel & {$[48]$} \\
\hline & & DMAPMA, NiPAm, MBAA & Bulk & [49] \\
\hline & $\mathrm{Ca}^{2+}$ or $\mathrm{Pb}^{2+}$ & NIPAm, MAA, MBAA & Gel & {$[50]$} \\
\hline & Atrial natriuretic peptide & NIPAm, MAA, MBAA & Particle & [51] \\
\hline & Cyt c or Lys & NIPAm, MAA, AAm, MBAA & Bulk & {$[52]$} \\
\hline & Adenine & NIPAm, MAA, EGDMA & Bulk & [53] \\
\hline & p-Nitrophenyl phosphate & NPP, DVB & Bulk & {$[54]$} \\
\hline & $\mathrm{BHb}$ & NIPAm, MBA & Core-shell & {$[55]$} \\
\hline & Sulfadiazine & NIPAm, EGDMA & Core-shell & {$[56]$} \\
\hline & Dopamine & MAA, AAM, MBAA & Particle & [57] \\
\hline
\end{tabular}


Table 1. Cont.

\begin{tabular}{|c|c|c|c|c|}
\hline Stimulus & Template & Monomer and cross-linker & Form of MIPs & Reference \\
\hline \multirow{9}{*}{ pH-responsive } & Propranolol & NIPAm, DMAEMA, EGDMA & Particle with brush & [58] \\
\hline & DXP & HEMA, DMAEMA, EGDMA & Particle & [59] \\
\hline & $(S)$-omeprazole & HEMA, PCL-T, EGDMA & Particle & [60] \\
\hline & \multirow{3}{*}{ Bisphenol-A } & AAc, acryloylamylose, MBAA & Powders & [61] \\
\hline & & PES, MBAA & Particle & [62] \\
\hline & & MAA, EGDMA & Layer & [63] \\
\hline & HVA & NIPAM, 4-VP, hemin, AAm, EGDMA & Particle & [64] \\
\hline & Diclofenac & MAA, MAAm, 4-VP, EGDMA & Bulk & [65] \\
\hline & Insulin & MAA, PEG, MBA & Bulk & [66] \\
\hline \multirow{17}{*}{ Photo-responsive } & Caffeine & MPABA, TRIM & Bulk & [67] \\
\hline & Bis(TBA)- $N$-Z-L-Glutamate & Di(ureidoethylenemethacrylate)azobenzene, EGDMA & Bulk & [68] \\
\hline & Caffeine or theophylline & $\begin{array}{l}\text { MPABA, 4-(dimethylamino)pyridine, triethylamine, } \\
\text { TRIM }\end{array}$ & bulk & [69] \\
\hline & Paracetamol & MAPASA, MBAA & Bulk & [70] \\
\hline & 1,3,5-Benzenetriol & MAPASA, TTT & Bulk & [71] \\
\hline & Porphyrin & Azobenzene, DVB, Styrene & Bulk & {$[26]$} \\
\hline & Propranolol & NIPAAm, MPABA, EGDMA & Particle with brush & [38] \\
\hline & \multirow{3}{*}{ 2,4-D } & DCPA-AZO-TESP, TEOS & Core-shell & [72] \\
\hline & & MAzoPy, EGDMA & Particle & {$[73,74]$} \\
\hline & & $\begin{array}{c}\text { 4-((4-(3-(trimethoxysilyl) propoxy) phenyl) diazenyl) } \\
\text { phenyl 2-(2,4-dichlorophenoxy)acetate, TEOS }\end{array}$ & Bulk & [75] \\
\hline & 4-HA & PES/PES-N $\mathrm{N}_{2}-\mathrm{NH}_{2}$ & Microfiber & [76] \\
\hline & \multirow{2}{*}{ Ibuprofen } & Azobenzene, EGDMA & Core-shell & [77] \\
\hline & & BPPO-AZO-TPPSP, TEOS & Bulk & [78] \\
\hline & Guanine & MAPDIA, TEAMA & Bulk & [79] \\
\hline & PAF & MANFAB & Bulk & [80] \\
\hline & BPA & MAPASA, EGDMA & Core-shell & [81] \\
\hline & DA & PhAAAn, TEGDA, EGDMA & Membrane & {$[82,83]$} \\
\hline \multirow{7}{*}{$\begin{array}{l}\text { Biomolecule- } \\
\text { responsive }\end{array}$} & Cyt C or Lys & NIPAm, MAA, AAm, MBAA & Bulk & [52] \\
\hline & Hydrocortisone & HEMA, EGDMA & Bulk & [84] \\
\hline & \multirow[b]{2}{*}{ AFP } & NSA, AAm, MBAA & Particle & [49] \\
\hline & & acryloyl-lectin, AAm, MBAA & Hydrogel & [85] \\
\hline & Thrombin & AM, MBAA & Hydrogel & [86] \\
\hline & DL-Norephedrine & & & \\
\hline & $\begin{array}{l}\text { Hydrochloride or } \\
\text { DL-Adrenaline hydrochloride }\end{array}$ & NIPAm, AAc, MBAA & Hydrogel & [87] \\
\hline \multirow{2}{*}{ Ion-responsive } & BSA & DMAPMA, NiPAm, MBAA & Bulk & [88] \\
\hline & Proton & NIPAm, AAc, MBAA & Particle & [89] \\
\hline
\end{tabular}

\section{Thermo-Responsive Molecularly Imprinted Polymers}

The biochemical processes of natural receptors, such as enzyme-catalysis, exhibit extremely sensitive dependence on temperature $[24,90]$. To simulate the temperature-dependent recognition and catalytic capacity, several thermo-responsive MIPs have been developed in parallel with a plethora of non-imprinted thermo-responsive polymers $[24,38,40]$. These polymers can exhibit either a lower critical solution temperature (LCST), below which they are a hydrophilic state, or an upper critical solution temperature, above which they are hydrophilic. The most widely studied synthetic thermo-responsive polymer is poly ( $N$-isopropylacrylamide) (PNIPAm), which undergoes a reversible phase transition at $32{ }^{\circ} \mathrm{C}$ (also called as Lower Critical Solution Temperature, LCST) in water, changing from hydrophilicity below the temperature to hydrophobicity above it $[43,91]$. The phase transition from soluble stretching polymer chain to insoluble coil-globule state is attributed to the decreasing enthalpic contribution of 
water hydrogen-bonded to the polymer chain in comparison to the enthalpic gain of the system with increasing temperature. Correspondingly, the phase transition from swollen state to collapsed state occurs in water when a moderate cross-linked PNIPAm network is used around the LCST [88,92]. This feature endows the MIPs containing PNIPAm blocks the fascinating property of regulatory binding capacity accompanied by the size changes of binding sites derived from temperature variation.

To date, PNIPAm has been the most employed synthetic polymer to prepare thermo-responsive MIPs, due to its LCST which is close to the temperature of the human body [93]. One of the earliest thermo-responsive MIPs was reported by Watanabe et al. [87]. The MIPs based on PNIPAm hydrogels were prepared via redox polymerization of NIPAm, AAc, MBA, and template such as DL-norephedrine hydrochloride or DL-adrenaline hydrochloride in 1,4-dioxane. The imprinted and non-imprinted gels showed a volume change in aqueous solution as a function of temperature but still retained the molecular recognition ability in the shrunken states. When the guest molecule was present in a saturated solution, the polymers exhibited another phase ("molecular recognition phase"), whose volume was responsive to the concentration of the guest molecule. Further on, Tanaka's group reported a similar imprinted polymer gel based on PNIPAm that swelled and shrank reversibly in response to temperature changes. The addition of a small amount of functional monomer such as methacrylamidopropyltrimethylammonium chloride (MAPTAC) resulted in gels able to capture target molecules such as pyranine-3 or pyranine-4 via a multiple-point electrostatic interaction [94]. From the relationship between swelling ratio and affinity of the gel as a function of temperature (Figure 2), it is seen that the recognition of the resulting polymeric gels towards the target molecule can be changed reversibly by more than one order of magnitude, accompanied by reversible swelling and shrinking of polymeric network in response to temperature. In their shrunken state, the imprinted sites of the gels exhibit higher affinity presumably due to the ability of the templates to ion-pair with three (pyranine-3, charge: $3-$ ) or four (pyranine-4, charge: 4-) MAPTAC monomers in the gel. While in the swollen state, the affinity of the imprinted sites decreases dramatically because MAPTAC monomers are well separated from one another, which means the target molecules can only be captured by MAPTAC with a single contact.

(a)

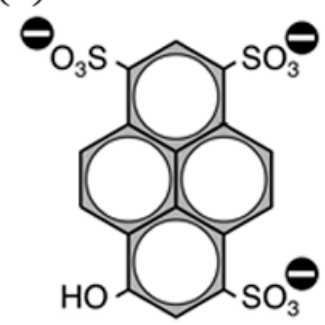

Pyranine-3

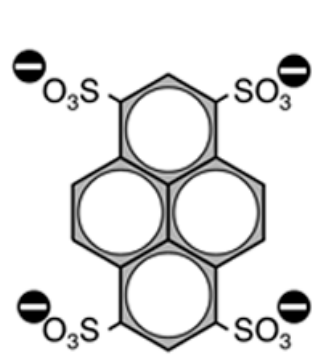

Pyranine-4

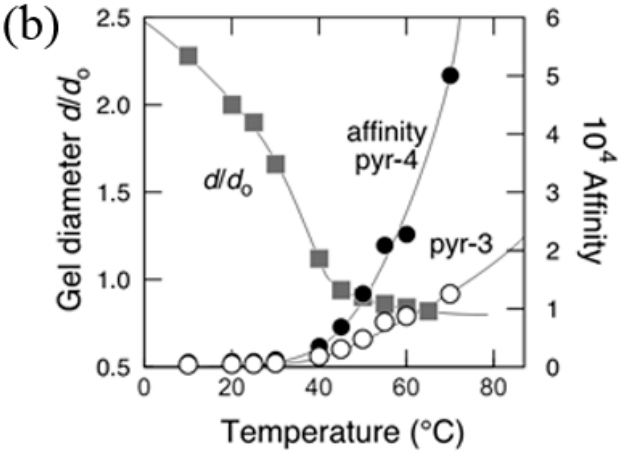

Figure 2. (a) The chemical structures of pyranine-3 and pyranine-4; (b) The affinity of the gels to pyranine- 3 and pyranine- 4 as a function of temperature. Reprinted with permission from Reference 94. Copyright 1999, Science.

This reversible molecular adsorption by using multiple-point interaction based on PNIPAm gels definitely provides a pioneering idea to prepare thermo-responsive MIPs, and the MIPs with reversible 
recognition towards various target molecules such as ions, small organic molecules, and even proteins were realized by using the same approach. Alvarez-Lorenzo et al. have reported a PNIPAm based temperature-sensitive polymeric gel to adsorb and release divalent ions reversibly by two-point interaction [50]. The imprinted gels prepared with calcium methacrylate (CaMAA2) or lead methacrylate (PbMAA2) showed higher affinity for target molecules as compared to randomly polymerized gels containing methacrylic acid (MAA) or lithium methacrylate (LiMAA) as functional monomers. Due to the reversible volume phase transition caused by temperature, the affinity decreased in the swollen state but recovered upon shrinking.

A slightly different procedure was also employed to prepare temperature-responsive imprinted polymers for capturing divalent cations or anions without using a template [95]. Besides the co-monomers mentioned above, the polymeric network was added with a cleavable cross-linker, such as $N, N$-cystaminebis(acrylamide) (BAC), whose disulfur bridges in the pendant cystamine groups can be cleaved and oxidized to form a pair of sulfonic functions, or 2,3-dihydroxy- $N, N, N^{\prime}, N^{\prime}$-tetramethyl $N^{\prime \prime}, N^{\prime \prime \prime}$-bis(3-((2-methylacryloyl)aminopropyl)-1,4-butanediammonium) dibromide, whose C-C with vicinal diol can be cleaved and leading to a pair of adjacent tertiary amines. Since the pair of sulfonic functions or adjacent tertiary amines located face to face with each other, the hydrogels prepared in this case were capable of specifically recognizing divalent cations or molecules containing two anionic functions, respectively.

Moreover, they showed significant volume phase transition and reversible recognition properties on varying the temperature. Liu et al. proposed thermo-responsive imprinted polymer gels capable of recognizing L-pyroglutamic acid (PGA) and 4-aminopyridine (APY) molecules [43] through multiple-pointelectrostatic interactions. The gels were synthesized starting from $N$-isopropylacrylamide and methacrylic acid as temperature-responsive and functional monomers, respectively. In their subsequent investigations, reversible recognition and release of target molecule are both realized by a change in temperature. Since the imprinted polymer hydrogels have good thermal responsivity, selectivity and reusability, they are potentially applicable in the separation field and in drug controlled release systems.

Recently, "on/off"-switchable catalysis by a smart enzyme-like thermo-responsive imprinted polymer was reported by Li et al. [54]. This unique imprinted polymer was also based on PNIPAm while being imprinted with $p$-nitrophenyl phosphate, a transition state analogue for the hydrolysis of the substrate $p$-nitrophenyl acetate. At a relatively low temperature (such as $20{ }^{\circ} \mathrm{C}$ ), the polymer networks were hydrophilic, enabling the substrate to access the catalytic sites resulting in enhanced catalytic efficiency in the hydrolysis of $p$-nitrophenyl acetate. On the contrary, at higher temperatures (such as $40{ }^{\circ} \mathrm{C}$ ), this polymer demonstrated a dramatically increased hydrophobicity, rendering the imprinted sites less accessible and hence resulting in poor catalysis. Thus, the polarity switch inherent in the use of a thermo-responsive PNIPAm endowed the polymer with a switchable catalytic activity.

In consideration with the application of MIPs in the biological field, some biomacromolecules, e.g., proteins have also been used as a template to design thermo-responsive MIPs [24,30,38,48]. A thermo-sensitive macroporous PNIPAm hydrogel showing selective recognition for lysozyme was developed by an imprinting procedure based on metal coordinate interaction [35]. In contrast to a traditional functional monomer, a metal chelate monomer ( $N$-(4-vinyl)-benzyl iminodiacetic acid) 
forming coordination complex with the template protein in the presence of $\mathrm{Cu}^{2+}$ was used. Finally, this imprinted hydrogel was used to purify the protein template from an artificial mixture of proteins and areal sample, in both cases resulting in a high selectivity. Another example of lysozyme imprinting based on a PNIPAm nanogel was proposed by Pan et al. [24]. AA and DMAPMA, containing a negatively charged carboxyl group and a positively charged tertiary amine group, respectively, were used as co-monomers and MBAAm as a crosslinker. Protein-imprinted spherical nanogel particles were readily prepared via aqueous precipitation polymerization. Compared to the non-imprinted counterparts, the lysozyme-imprinted nanogels possessed higher rebinding capacity, more rapid rebinding kinetics, and a much higher specificity toward lysozyme. Importantly, both the rebinding and release characteristics of lysozyme-imprinted nanogels showed dramatic temperature-dependence, with clear on-off transition around $33{ }^{\circ} \mathrm{C}$. Hua et al. reported on a temperature-sensitive protein-imprinted hydrogel based on PNIPAm by using $N$-(3-(Dimethylamino)propyl)-methacrylamide (DMPMA) as functional monomer and bovine serum albumin (BSA) as a template through electrostatic interaction [88]. After removal of the template proteins by treatment with $500 \mathrm{mM}$ aqueous $\mathrm{NaCl}$ solution, the polymer affinity to recognize the target protein was greatly influenced by external stimuli, such as temperature and ionic strength. The authors found that the optimal binding conditions (maximal affinity toward the template) were very close to the original imprinting state, proving that the origin of the specificity relied on the spatial integrity of the recognition site formed in the imprinting process. The changes in gel volume result in a decreased affinity of the MIPs.

Considering the similarity with NIPAm, TBAm [47] and MBAAm [57] were also used as thermo-responsive co-monomers in MIPs to achieve responsive molecular recognition. TBAm has proven to be a temperature sensitive monomer that allowed for swelling and shrinking of the hydrogels in response to temperature [96]. According to this, Demirel et al. prepared poly(N-tert-butylacrylamide-co-acrylamide/maleic acid) imprinted hydrogels for recognizing BSA with a thermo-responsive performance [47]. Adsorption studies also showed that other stimuli, such as $\mathrm{pH}$ and initial BSA concentration, also influenced the BSA adsorption capacity of the MIP hydrogels. In the same manner, temperature sensitive binding capacity of dopamine-imprinted MBA cross-linked polymers was observed in $80 \%$ aqueous methanol solution around $35{ }^{\circ} \mathrm{C}$ by Suedee et al. [57]. Subsequently, the resulting MIP was tested for its application as a sorbent material of solid-phase extraction (SPE), utilizable in the selective extraction of dopamine from urine samples mixing with other adrenergic compounds (epinephrine, isoproterenol, salbutamol and serotonin).

The above literature showed that the introduction of thermo-responsive co-monomers into the networks of MIPs was a general and efficient approach to fabricate thermo-responsive MIPs. Nevertheless, it is accompanied by a number of disadvantages. One obvious problem is the greater complexity of the self-assembly system between template and functional monomers caused by the addition of NIPAm. This, together with the decreased proportion of functional monomers, should lead to a lower affinity compared to conventional imprinted polymers without PNIPAm blocks. The problem is ubiquitous and similar to the development of water-compatible MIPs, whose affinity would be largely affected by the addition of hydrophilic co-monomers. Another problem is the contradiction between the affinity and the responsiveness of this kind of MIPs. One of the most attractive features of MIPs is their robustness with respect to reusability and compatibility with a range of solvents and 
test conditions. These properties depend strongly on the degree of cross-linking in the MIP. On the other hand, the volume inversion of PNIPAm based MIPs will be greatly limited in a case of a robust polymeric network, subsequently leading to a poor responsiveness to temperature. Overall, using this method, complicated and time-consuming optimizations are necessary for preparing a well-performing thermo-responsive MIP.

Recently, Pan et al. reported a novel approach to prepare both thermo-responsive and water-compatible MIP microspheres by the facile surface-grafting of PNIPAm brushes via RAFT polymerization [36] (Figure 3). The reported method demonstrated an efficient approach to avoid the disadvantages of PNIPAm based MIPs mentioned above by grafting a high-density layer of linear PNIPAm on the surface of preformed MIP microspheres. Distinctively, the hydrophilic/hydrophobic conversion on the surface of MIPs microspheres caused by the thermo-responsive PNIPAm brushes leads to a thermo-responsive binding property. Moreover, unlike those described above, the approach only requires the facile PNIPAm-grafting on the preformed MIP microspheres and no PNIPAm blocks in the imprinted network, thus avoiding many complicated and time-consuming optimizations for MIPs formulations and making the preparation more flexible. This represents a novel and promising way to develop advanced MIP materials not only with thermo-responsive binding property, but also with other stimuli-responsive properties such as when replacing the thermally responsive polymer with a $\mathrm{pH}$ or light sensitive polymer, etc.

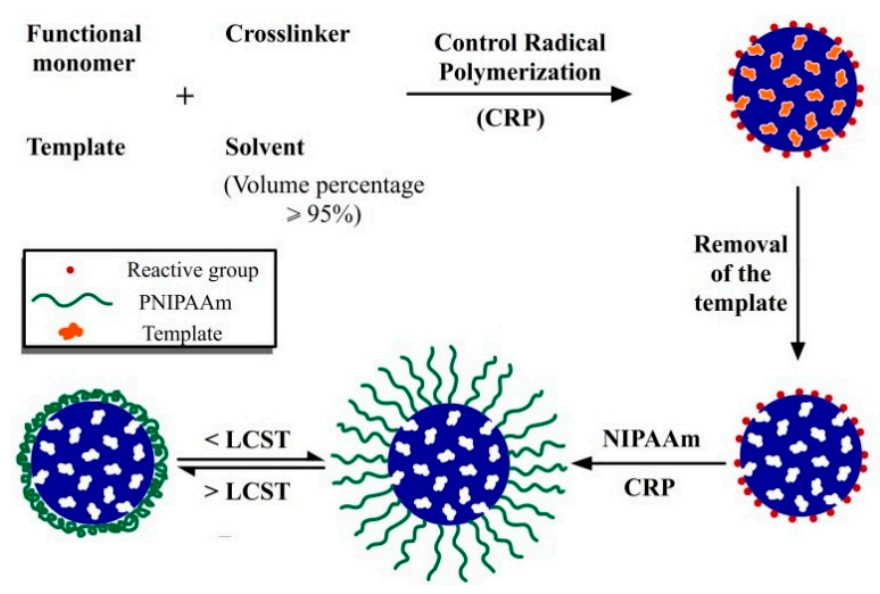

Figure 3. Protocol for the preparation of water-compatible and stimuli-responsive MIP microspheres with surface-grafted functional polymer brushes. Reprinted with permission from Reference 36. Copyright 2010, Elsevier.

Furthermore, by the combined use of PNIPAm brushes on the surface and PNIPAm blocks into the imprinted network, Qin et al. prepared a molecularly imprinted bead with double thermo-sensitive gates for selective recognition and release of proteins [33]. The MIP beads were prepared by two-step surface-initiated iniferter polymerization on mesoporous chloromethylated polystyrene (MCP) beads, which formed double layers, an internal thermo-sensitive lysozyme imprinted layer, and an external linear PNIPAm brush layer. The two layers showed different volume phase transition temperature. At $43{ }^{\circ} \mathrm{C}$, the outer linear PNIPAm layer and the inner imprinting layer were all collapsed, resulting in a hydrophobic shell and distorted recognition sites in the core, respectively. This led to nonspecific 
protein binding on the MIP bead surface. When the temperature changed to $38{ }^{\circ} \mathrm{C}$, the MIP bead expanded to form a hydrophilic PNIPAm shell and a spatial integrity of the internal recognition site in the core, so a suppression of nonspecific protein binding was observed accompanied by improved specific protein binding. At even lower temperatures around $23{ }^{\circ} \mathrm{C}$, the internal recognition site showed a more swollen state and a weak binding capacity to the template protein. The results further indicate that fabricating the thermo-sensitive surface layer or the interior imprinted sites for the MIPs can both create thermo-responsive binding capacity in spite of their different manner and different effect. Besides, if we regulate the performance (e.g., an identical volume phase transition temperature) of the surface and interior of MIPs to an optimal level, fantastic thermo-responsive MIPs could be obtained.

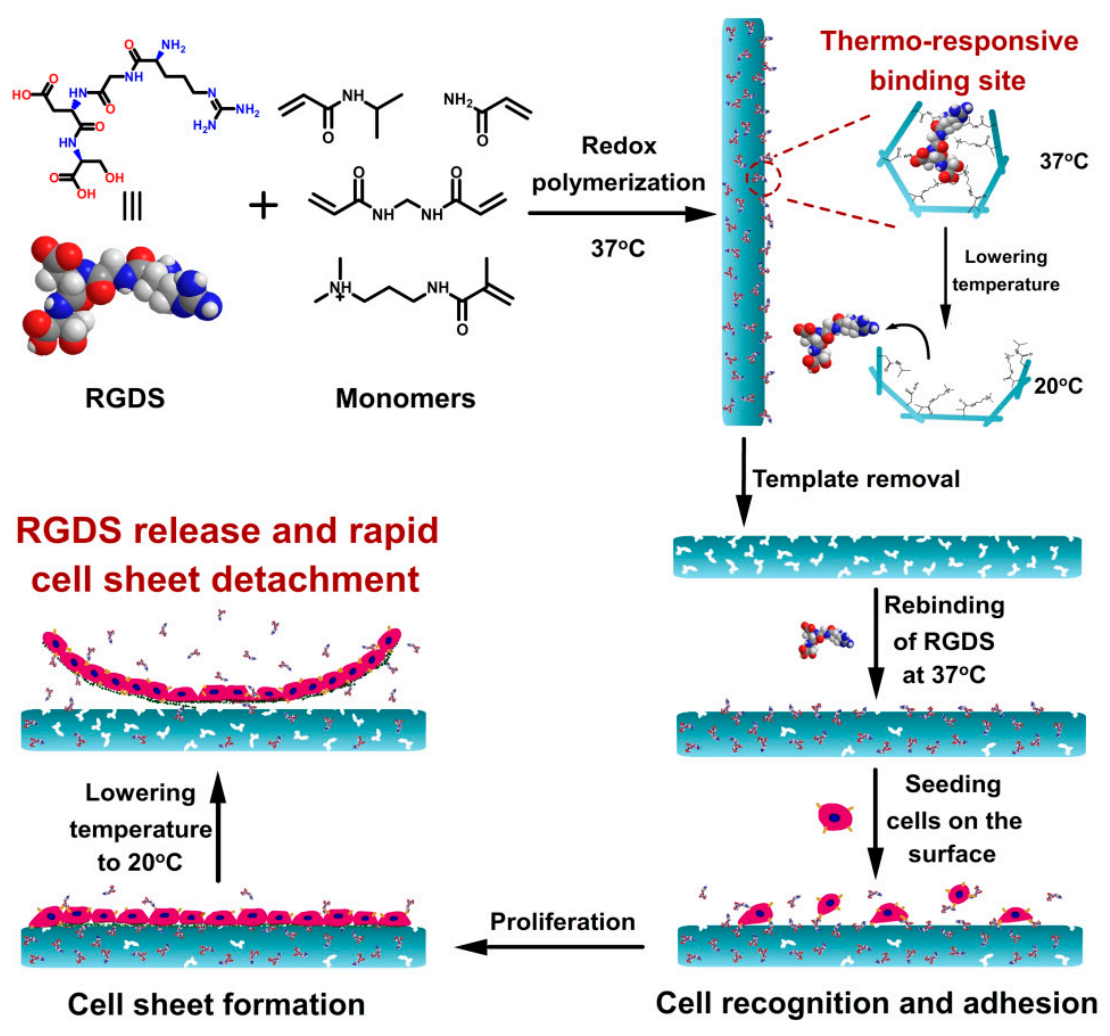

Figure 4. Strategy to introduce the RGDS peptide to a thermo-responsive cell culture substrate by means of molecular imprinting and the schematic illustration for the cell adhesion and the harvesting of a cell sheet. Reprinted with permission from Refence 37. Copyright 2013, Wiley.

To enhance cell adhesion during culture and facilitate the rapid harvest of cell sheets, Pan et al. reported a novel system for harvesting cell sheets which relies on a PNIPAm-based MIP hydrogel layer with thermo-responsive affinity toward specific biomolecules by redox-initiated polymerization (Figure 4) [37]. Molecular imprinting methodology was employed to introduce the cell-adhesive peptide RGDS onto a thermo-responsive cell culture substrate, which was innovatively used as a highly efficient novel system for harvesting cell sheets. With the reversible thermo-responsive "specific recognition sites", the imprinted hydrogel could recognize and bind RGDS molecules at a temperature common for cell culture $\left(37^{\circ} \mathrm{C}\right)$, and then rapidly release RGDS when the temperature was lowered. Compared with simple physical absorption and covalent immobilization approaches, the thermo-responsive "specific 
binding" in the imprinted hydrogel promotes cell adhesion during cell culture and facilitates cell detachment during cell sheet harvest.

\section{3. pH-Responsive Molecularly Imprinted Polymers}

Weak polyelectrolytes, such as poly(carboxylic acid) [97], poly(phosphoric acid) [98] and polyamine [99], contain ionizable groups and are able to accept or donate protons at a specific $\mathrm{pH}$. These $\mathrm{pH}$-sensitive polymers exhibit a conformational change upon variation of the $\mathrm{pH}$ which translates into swelling/shrinking behavior when present as gels. Such hydrogels are the most common candidates for $\mathrm{pH}$-responsive systems. In addition, dendrimers such as polyethyleneimine (PEI) modified with methacryl groups was can also reversibly be opened and closed in response to $\mathrm{pH}$ [100]. Therefore, MIPs based on $\mathrm{pH}$-responsive polyelectrolytes should demonstrate $\mathrm{pH}$-dependent recognition and such systems have therefore been considered as promising materials for controlled drug delivery [59,60,101].

In molecular imprinting, functional monomers like acrylic acid (AAc), methacrylic acid (MAA), maleic acid (MA), and $N, N$-dimethylaminoethyl methacrylate (DMAEMA) are often used in order to provide interactions between the polymer and template molecules through hydrogen bond or charge complementarity. Hence, MIPs with the recognition relying on hydrogen bonding or electrostatic interactions always exhibit a $\mathrm{pH}$-responsive binding capacity caused by the $\mathrm{pH}$-induced change of the interaction between templates and the imprinting sites.

Based on this principle, a spherical MIP has been reported by Puoci et al. as a $\mathrm{pH}$-sensitive sustained drug release system for sulfasalzine using MAA as the functional monomer and EGDMA as the cross-linker, respectively. In addition to displaying a more sustained release period compared to then on-imprinted polymers, the imprinted polymers also showed a different release rate at different $\mathrm{pH}$ values. When the MIPs were placed in a media with the $\mathrm{pH}$ change from 1 to 6.8 , a sudden release of sulfasalzine was observed. This can be explained by the carboxylic groups situated at imprinted sites being ionized at $\mathrm{pH}$ values higher than their average $\mathrm{p} K_{\mathrm{a}}$. In this state, they do not interact with the template (sulfasalazine) through hydrogen bonding. To expand the application of spherical MIPs for biological samples, the author further prepared a $p$-acetaminophenol (AMP) imprinted polymer with a hydrophilic external layer, which led to a drastic reduction of protein absorption, hence referred to as a restricted access material [102]. When tested as controlled release device in gastrointestinal simulating fluids, the new polymers showed a $\mathrm{pH}$-responsive release, which further confirmed the release mechanism based on the ionization of carboxylic acid groups. The same effect has been observed in some drug delivery systems based on MIPs.

Other acidic monomers such as maleic acid (MA) have also been used to obtain $\mathrm{pH}$-responsive MIP [47]. Since it is analogous to MMA and was mentioned in the last section, it will not be presented here reduplicatively. In contrast to the previous systems, Wang et al. described another $\mathrm{pH}$-sensitive MIP nanospheres/hydrogel composite for controlled releasing of dexamethasone-21 phosphate disodium (DXP) [59]. The MIP nanospheres based on a basic functional monomer, DMAEMA, exhibited a faster DXP release rate in a $\mathrm{pH}$ range of 6.0-7.4, which is an inspiration for suppressing inflammation because inflammation induces an acidic microenvironment. The $\mathrm{pH}$-responsive release process mainly resulted from the variable ionic interaction (electrostatic interaction) between DXP and DMAEMA in response to $\mathrm{pH}$ value. Incorporating the MIP nanospheres into a preformed 
poly (2-hydroxyethyl methacrylate (HAMA)- $N$-vinyl-2-pyrrolidinone (NVP)-2-methacryloyloxyethyl phosphorylcholine (MPC)) hydrogels formed a $\mathrm{pH}$-sensitive MIP nanospheres/hydrogel composite, which can be designed as a coating on implantable biosensors for potentially suppressing the inflammation. Recently, the metal coordinate bond strategy was also used to fabricate MIH with $\mathrm{pH}$-responsive property and controlled release capacity in aqueous phase. Zhang et al. prepared a smart MIH by using 2-hydroxyethylmethacrylate (HEMA) and MBA as backbone and cross-linker respectively in the presence of Dox- $\mathrm{Cu}^{2+}-4-\mathrm{VP}$ complex [25]. The MIH showed a $\mathrm{pH}$-responsive release property, not more than $10 \%$ of loaded drug was released from Dox-MIH at $\mathrm{pH} 7.2$ in seven days. In contrast, near to $60 \%$ of loaded drug was released at $\mathrm{pH} 5.0$ during the same period. These results indicated that Dox-MIH with $\mathrm{pH}$-responsive behavior possessed great promise as a sustained-release delivery system of anticancer drugs.

Another approach to realizing $\mathrm{pH}$-responsive binding or releasing property is to exploit the swelling/shrinking behavior of the imprinted hydrogels upon variation of $\mathrm{pH}$ values. For instance, Kanekiyo et al. designed a novel pH-responsive MIPs by using acrylic acid (AA) as an ionizable comonomer and acryloylamylose as a functional monomer [61], respectively, and the latter can form a helical inclusion-complex with template molecule (BPA) through hydrophobic interaction in aqueous solution [103] (Figure 5). The ionizable unites (carboxyl group) of the amylase-based MIPs displayed a reversible structural change of the imprinted binding sites upon varying the $\mathrm{pH}$ of the solution, ultimately leading to $\mathrm{pH}$ dependent binding of the template.

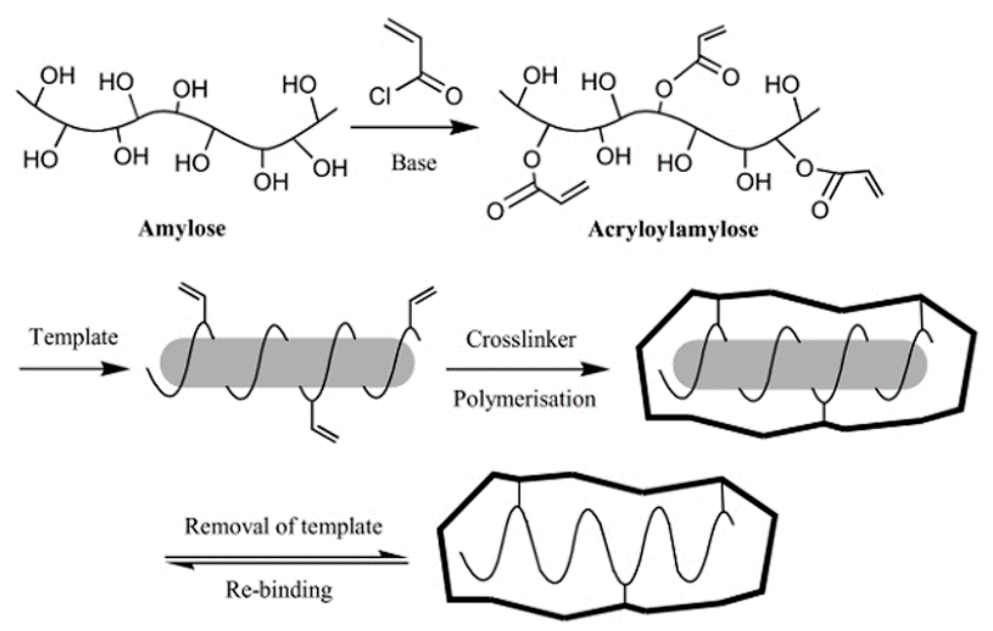

Figure 5. Outline of molecular imprinting using amylose. Reprinted with permission from Reference 103. Copyright 2002, Royal Society of Chemistry.

Similarly, Oral et al. reported $\mathrm{pH}$-responsive and recognitive polymeric networks based on PEG star polymers to distinguish D-glucose from similar sugars by using methylacryl acid (MAA) as the ionizable comonomer [104]. In addition, equilibrium swelling and rebinding properties of BSA imprinted hybrid hydrogel microspheres based on calcium alginate and phosphate were also evaluated in different $\mathrm{pH}$ values and even ionic concentrations [105]. Recently, this type of pH-responsive imprinted hydrogels was applied as horseradish peroxidase mimetic enzymes. The novel enzyme-like catalytic system was based on an imprinted tetrapolymer of 4-vinylpyridine (4-VP), chloro (3,7,12,17-tetramethyl-8,13-divinylporphyrin-2,18-dipropanoato(2-))iron(III) (hemin, used as the 
catalytic center), AM, and NIPAm cross-linked by EGDMA with homovanillic acid as the template molecule. Under optimal $\mathrm{pH}$ conditions (close to the $\mathrm{pI}$ of the polymer), the imprinted gel shrunk to the smallest size with an excellent hydrophobic microenvironment in the imprinted nanostructures, which significantly increased the catalytic efficiency (Figure 6). This remarkably sensitive catalysis in response to $\mathrm{pH}$ conditions shows us an effective way to modulate the microenvironment around the catalytic centers for mimetic enzyme [64].

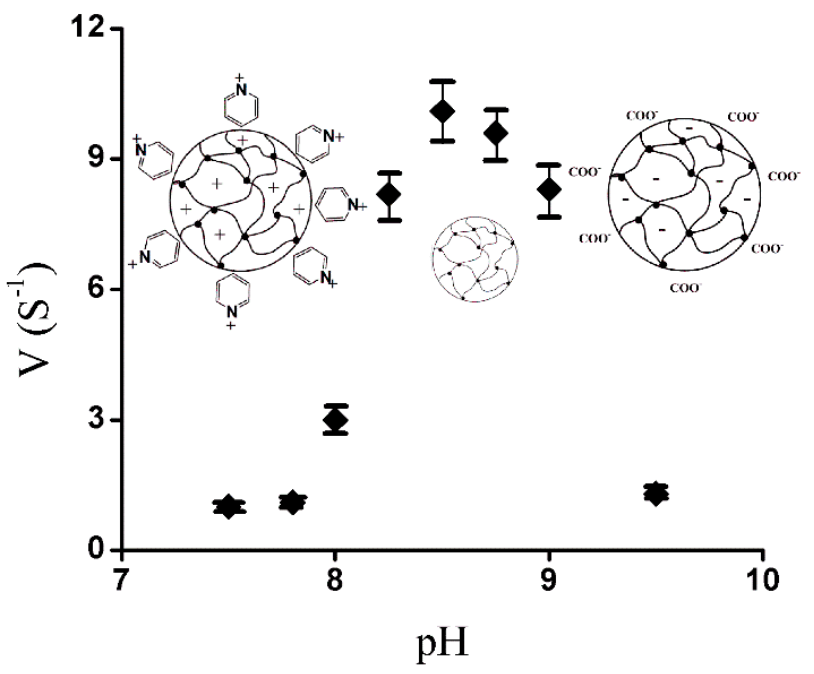

Figure 6. $\mathrm{pH}$ effect on the catalytic rate of the imprinted hydrogels in Tris- $\mathrm{HCl}$ buffer. Reprinted with permission from Reference 64. Copyright 2010, Wiley.

Post-modification of performed MIPs with $\mathrm{pH}$-responsive polymers can also allow obtaining a $\mathrm{pH}$-dependence binding capacity. Zhao et al. reported a $\mathrm{pH}$-responsive MIP particles fabricated by pore-filling poly (acrylic acid) (PAA) gels into BPA-imprinted polyether sulfone particles [62]. The $\mathrm{pH}$-dependence swelling and shrinking of the PAA gels in the MIPs particles gave rise to reversible control of the rebinding ability toward BPA due to the volume exclusion effect. Despite of a decrease in the adsorbed BPA amount (or rate) after filling the PAA gels, the methodology demonstrated a novel strategy to create $\mathrm{pH}$-responsive MIPs as smart chemicals and as drug-delivery systems.

Soon afterwards, Suedee et al. fabricated a pH-responsive controlled-release drug device based on a synthesized composite latex, which was consisted of a $\mathrm{pH}$ stimuli-responsive poly (hydroxyethyl methacrylate) (HEMA) and polycaprolactone-triol (PCL-T) blend, and a MIP with preloaded drug, $(S)$-omeprazole. The pH-responsive releasing of $(S)$-oeprazole was due to the PHEMA polymer in the composite latex, which was mainly functioned as a barrier to provide sustained release of the required $\mathrm{pH}$-dependent drug. Moreover, the results demonstrate that drug delivery systems containing $(S)$-omeprazole imprinted nanoparticles displayed maximum efficacy while minimizing dose frequency [60].

\section{Photo-Responsive Molecularly Imprinted Polymers}

Photo irradiation is one of the most frequently adopted external stimuli for stimuli-responsive polymeric materials. Those photo-sensitive materials commonly contain photosensitive chromophores, such as azobenzene [106], stilbene [107], spiropyran and spitooxazines [108] and fugides [109]. 
Amongst the numerous photosensitive chromophores, the UV-visible photo-induced trans-cis isomerization of azobenzene and its derivatives is probably the most extensively studied for its chemical stability, large change in dipole [110], and high quantum yield [111]. The azobenzene chromophore exhibits two isomeric states, the thermodynamically more stable trans-isomer and the meta-stable cis-isomer. The trans-form is converted into the cis-isomer by UV light irradiation or heat, and the cis-isomer can return to the trans-form photo-chemically under visible light irradiation or thermally in the dark (Figure 7). Since the trans-cis photoisomerization of azobenzene brings about large changes in molecular geometry and dipole moment to the chromophore [112], when the azobenzene chromophore was incorporated into imprinted receptor sites, the photo-induced changes in orientation and space should result in a significant alteration of receptor geometry and, consequently, affect the binding capacity of the host-guest.
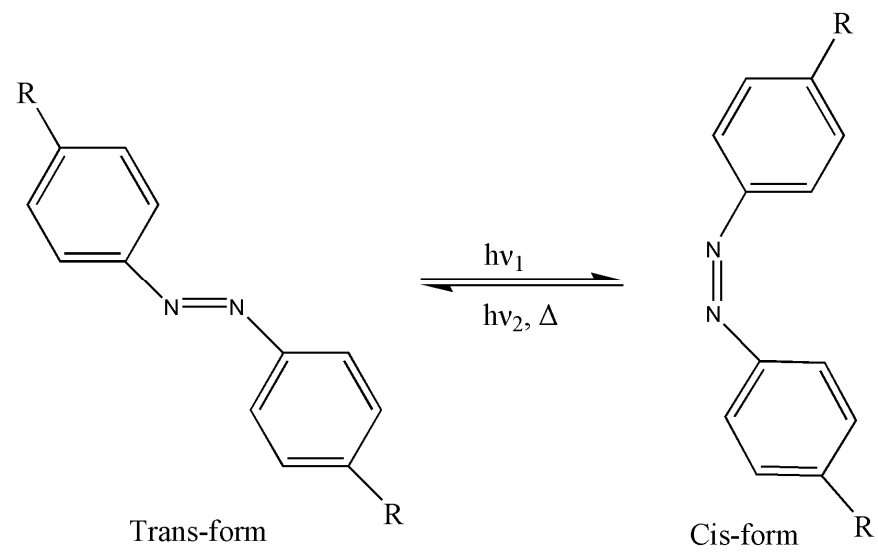

Figure 7. Schematic figure of the trans-cis isomerization of azobenzen.

The first successful precedent for designing photo-responsive MIP membrane was demonstrated by Minoura et al. using a derivative of azobenzene, $p$-phenylazoacrylanilide (PhAAAn). The mixtures of EGDMA and tetraethylene glycol diacrylate (TEGDA) were used as the cross-linkers due to the formation of mechanically stable, but flexible, polymer membranes. Since photo-isomerization of a chromophore had a great influence on the binding site, the resulted MIP membranes exhibited a reversible absorption/release of the template dansylamide (DA), and a better selectivity towards its analogue, dansyl-L-leucine (DL) and N,N-dimethylnaphthylamine (DMN). However, the binding capacity and the selectivity of the MIP membranes were not high, which may be attributed to the weaker interactions between the azobenzene functional monomers and target molecules [82].

For the purpose of a more powerful interaction between template and functional monomer, Gong et al. employed an novel azobenzene-based functional monomer, 4-((4-methacryloyloxy)phenylazo)benzoic acid (MPABA), which contained a carboxyl group on the para-position of benzene ring [67]. The authors made a detailed study on the influence of cross-linker/monomer ratio, and found that lower cross-linker/monomer ratios (e.g., 1:1 and 3:1) displayed no photo-isomerization properties, which was attributed to the higher chance for azobenzene monomers to aggregate and pack with each other, leading to the reduction of free volume necessary for the reorientation of azobenzene chromophores during their isomerization. The optimized bulk MIP material possessed the ability of reversible release and caffeine 
uptake more than four times greater upon irradiation at 365 and $440 \mathrm{~nm}$, respectively, which demonstrates its potential applications in smart separations and drug delivery systems.

Various interactions have been employed in photo-responsive molecular recognition systems. By the same group, a water-soluble azobenzene-containing functional monomer 4-((4-methacryloyloxy)phenylazo) benzenesulfonic acid (MAPASA) was developed for the fabrication of a photo-responsive molecularly imprinted hydrogel material through electrostatic interaction [70]. The photo-responsive MIP hydrogels were designed by cross-linking with various bisacrylamide and bismethacrylamide. The results showed that the photo-isomerization was greatly related to the spacer length of the both ends of the cross-linkers, that is the rate of photo-isomerization gradually increased with spacer length. However, the template binding capacity of the imprinted receptors dropped with the increasing flexibility of the hydrogels. In an optimal condition, the MIP hydrogels showed excellent specific binding capacity and repeatable photo-regulating release/uptake properties in biocompatible aqueous media. In addition, the relative low cross-linking degree and good optical transparency in aqueous media awarded the MIPs hydrogels faster photo-responsive rate, moreover, the use of water-soluble functional monomer and cross-linkers demonstrated their wider applications in the biological field. Li et al. also used a water-soluble azobenzene derivative containing two carboxylic acid groups (-COOH), 5-((4-(methacry-loyloxy)phenyl) diazenyl)isophthalic acid (MAPDIA) as the functional monomer, and developed a photo-responsive MIP for guanine using a new water-soluble triethanolaminetrimethacrylate (TEAMA) as the cross-linker [79]. The MIP can release and take up guanine with irradiation at 365 and $440 \mathrm{~nm}$, respectively. In addition, the MIP was successfully applied to the photo-controlled solid-phase extraction of guanine from complex real samples (beer) with good recovery. Subsequent photo-controlled release of guanine in aqueous media allowed for convenient quantitative analysis with high efficiency.

Recently, Gong also demonstrated a new photo-responsive molecular recognition system for 2,3,4,5,7,8,9,10-octafluorophenazine (PAF) uptake through fluorine-fluorine interaction [80]. The new kind of photo-responsive functional monomer containing fluorine-substituted azobenzene chromophore, named (4-methacryloyloxy)nonafluoroazobenzene (MANFAB), was designed and synthesized for the MIPs. The reversible release and uptake of PAF from toluene can be photo-regulated by alternate irradiation at 315 and $440 \mathrm{~nm}$, indicating a possibility for photo-responsive molecular recognition directed by fluorine-fluorine interaction. In addition, Takeuchi et al. synthesized a novel photo-responsive functional monomer bearing diaminopyridine and azobenzene moieties, which was applied to the preparation of photo-regulated MIPs for recognizing porphyrin derivatives carboxylic acids through hydrogen bonding [26]. Gomy et al. designed a photo-responsive cross-linker with bisurea binding functionalities serving as well as a functional monomer towards dicarboxylate moieties (Figure 8) [68]. Despite of the rigid polymer, the photo-isomerization properties of the azobenzene chromophore are retained. This new approach to form imprinted sites can be used for non-covalent MIPs preparation with potential improved performance, so that more functionality can be introduced without suffering affinity performance losses due to reduced cross-linking. 


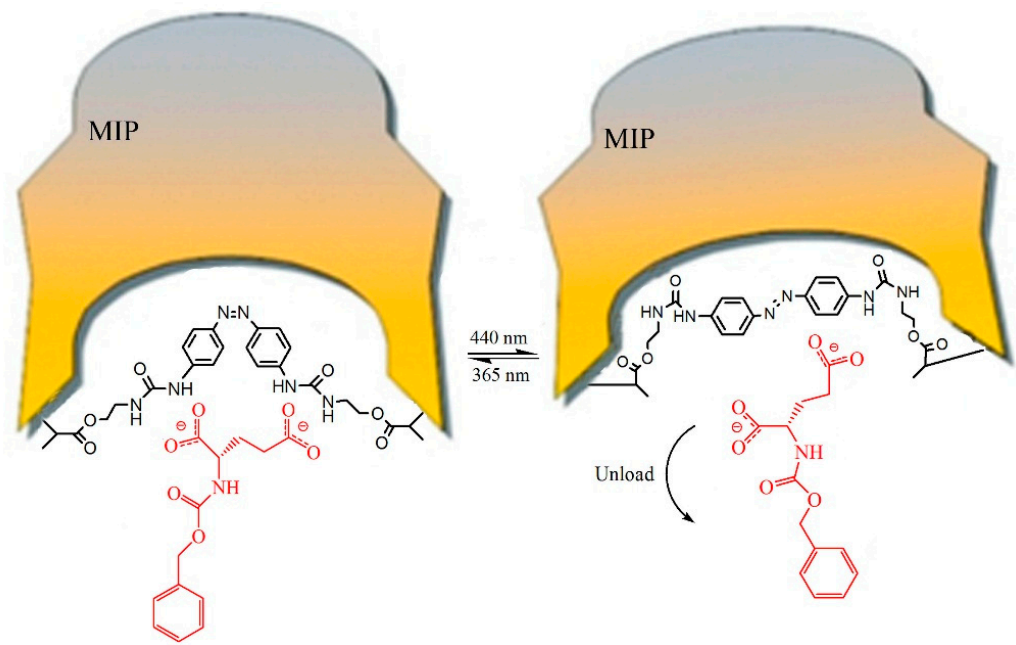

Figure 8. Photoisomerization of the MIPs matrix allowed switching the substrate affinity by altering the geometry and spatial arrangement of the receptor binding sites. Reprinted with permission from Reference 68. Copyright 2007, ACS.

For photo-responsive materials, the efficient area of irradiation on the materials is one of the most crucial factors for rapid and high-efficiency photo-isomerization. Therefore, besides the materials with a great transparency [70] or prepared as a membrane with large exposed area, micro/nano-particle materials are also appropriate candidates for photo-responsive MIPs because of their large specific surface area. However, photo-responsive bulk MIPs always need a time-consuming grinding and sieving procedure to particles, as well leading to great loss of binding sites [113]. Precipitation polymerization has proven very versatile for preparing MIPs micro-/sub-microspheres for its easy operation and lack of need for any surfactant or stabilizer. Recently, Fang et al. described a successful preparation of azobenzene (azo)-containing MIP microspheres with photo-responsive template binding properties via precipitation polymerization [74]. The photo-responsive MIP microspheres with a number-average diameter of $1.33 \mu \mathrm{m}$ and a narrow polydispersity exhibited obvious molecular recognition effects towards 2,4-dichlorophenoxyacetic acid (2,4-D), such as fast template rebinding kinetics and appreciable selectivity over structural analogue. More importantly, the photo-regulation process of the MIP microspheres had also proven to be highly repeatable under photo-switching conditions, leading to obvious photo-responsive binding properties towards the template molecule. Very recently, molecularly imprinted organic-inorganic hybrid azobenzene nanoparticles were synthesized by semi-covalent approach for radiation induced selective recognition of 2,4-D [75]. The hybrid MIP particles were prepared by polymerizing TEOS with a silane containing azobenzene and template molecule via a hydrolysis-condensation mechanism. Removal of the template molecules, the MIP materials were able to release and uptake 2,4-D upon irradiation at 360 and $440 \mathrm{~nm}$, respectively. Moreover, the concentration of 2,4-D can be quantified by monitoring the trans-to-cis photo-isomerization rate constant.

In a word, the successful preparation of photo-responsive MIPs through various interactions and in different physical formats demonstrate their tremendous potential applications in a range of fields, such as smart separation, extraction, and assays, intelligent chemical carriers, and catalysis etc. However, there are still several disadvantages for the current photo-responsive MIPs. To date, azobenzene chromophore is the most adopted and efficient photo-isomerization group in the molecular imprinting 
field. Considering the high toxicity of azobenzene, the existence of azobenzene groups in imprinting polymeric network will tremendously limit their applications in vivo, such as drug delivery systems. Furthermore, the current photo-responsive MIPs are confined to the photo-regulatory of imprinted sites, so that the ratios of photo-isomerization show great diversity due to their physical properties, such as the size, photo-permeability and the degree of cross-linking. Similarly to some thermo- and pH-responsive MIPs, we may fabricate a photo-responsive polymer layer onto the surface of preformed and optimized MIPs, and realize a photo-regulatory derived from the surface of MIPs. Since a successful precedent has been done for reversible photo-regulation of enzyme activity by using a photo-responsive azobenzene polymer chain pendant [114], the suggested approach could be a promising way to overcome the disadvantages of current photo-responsive MIPs, such as the limited ratios of photo-isomerization and complexity of imprinting systems.

\section{Biomolecule-Responsive Molecularly Imprinted Polymers}

The physiological reactions are closely related to a variety of biomolecules. For example, the releasing of insulin from secretory cells is regulated by complex cell signal based on the changes of physiological sugar concentration. To mimic those natural feedback systems, a few studies on the preparation of stimuli-sensitive materials that directly respond to a specific molecule have been reported.

Biomolecule-sensitive MIPs were firstly reported by Watanabe et al., which was mentioned in the section of thermo-responsive MIPs. The imprinted polymers based on PNIPAm exhibited a temperature-dependence volume change and a molecular recognition phase, whose volume was responsive to the concentration of the guest molecule [87]. Other biomolecule-responsive MIPs were investigated by Sreenivasan et al. for the release of testosterone in response to the concentration of hydrocortisone, which was used as the template molecule and able to replace the stronghold of testosterone in the imprinted sites leading to a hydrocortisone-responsive releasing way [84]. To date, the most classic example for biomolecule-responsive MIPs is the dynamic biomolecule recognition of glycoprotein-imprinted gel using lectin and antibody molecules as ligands for a target tumor marker glycoprotein [49]. The bioconjugated imprinted gels can recognize saccharide and peptide chains in tumor specific marker glycoprotein ( $\alpha$-fetoprotein (AFP)), which lead to a shrinking behavior of imprinted gels. Furthermore, the same group designed a DNA-responsive gels by the same biomolecular imprinting approach [85]. The DNA-responsive shrinking of the imprinted gel was caused by the formation of the DNA duplex that acted as reversible cross-linking points. The swelling ratio of DNA-imprinted gels was strongly dependent on the sequence of DNA in a buffer solution. Since the DNA-imprinted gels can sense single-nucleotide polymorphisms and induce their structural changes, they may prove useful for many potential applications such as smart devices in sensing systems and for molecular diagnostics and drug delivery. Besides these commonly used methods, some novel strategies have been reported to prepare responsive MIP. Bai et al. prepared a new type of aptamer-based hydrogel with specific response to target proteins [86]. The volume shrinking of the superaptamer hydrogels is visible to the naked eye in response to femtomolar concentrations of protein (Figure 9). These materials open up new avenues for the design of improved materials for molecule-specific responsive polymers that can ultimately be used for biosensors, drug delivery, and responsive micro-devices. 

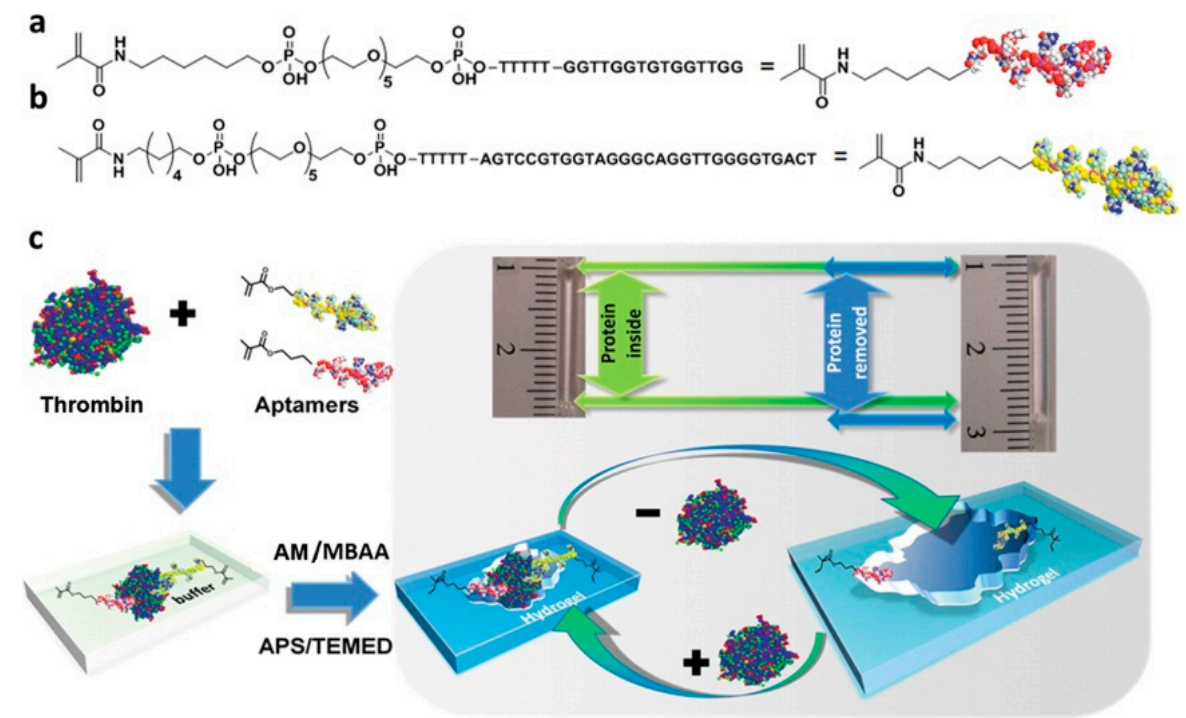

Figure 9. Outline of the biomolecular imprinting scheme used to create superaptamer thrombin-responsive hydrogels. Reprinted with permission from Reference 86. Copyright 2013, ACS.

\section{Ion-Responsive Molecularly Imprinted Polymers}

Currently, ion-responsive molecularly imprinted polymers are rarely reported. As mentioned above, the PNIPAm-based hydrogels undergo volume changes in response to the ionic strength, leading to ion-responsive binding properties. Intriguingly, $\mathrm{Chu}$ et al. reported a molecular-recognition microcapsule for ion-responsive controlled release, which may bring us some inspirations for the preparation of ion-responsive MIPs [115]. The reported ion-responsive microcapsule is composed of a core-shell porous membrane and linear grafted poly ( $N$-isopropylacrylamide-co-benzo-18-crown[6]-acrylamide) (PNIPAm-co-PBCAm) chains in the pores acting as molecular-recognition gates. Benzo-18-crown[6] acrylamide (BCAm) is a crown ether receptor, which allows ionic molecular recognition. When specific guest molecule such as $\mathrm{Ba}^{2+}$ is captured by the crown ether host, the grafted polymer swells and closes the pores. To the contrary, when $\mathrm{Ba}^{2+}$ is removed from the crown ether host, the grafted polymer shrinks and then the pores open. The changes lead to a release of solute from the prepared microcapsules significantly sensitive to the existence of $\mathrm{Ba}^{2+}$ ions. Significantly, the prepared poly (NIPAm-co-BCAm)-grafted microcapsules showed us an excellent approach to design ion-responsive MIPs by a surface grafting of MIPs with similar functional polymers. Taking advantage of the ion-imprinting strategy, Yu Hoshino et al. developed proton-imprinted nanoparticles using NIPAm and AAc as comonomer by pseudo-precipitation polymerization (Figure 10). The $\mathrm{p} K_{\mathrm{a}}$ variation range was up to 2.2 which is significantly larger than that of the nonimprinted NPs. More importantly, the apparent $\mathrm{p} K_{\mathrm{a}}$ value of the proton-imprinted particles reversibly shifted up and down without significant changes in the $\mathrm{p} K_{\mathrm{a}}$ variation range during repeated shrinking (heating, $75^{\circ} \mathrm{C}$ ) and swelling (cooling, $30^{\circ} \mathrm{C}$ ) cycles. The principles employed in the preparation of proton-imprinted nanoparticles can be used to other stimuli-responsive materials and will be an integral step in the creation of active proton transporters that enable effective ion transport, gas separation, and catalytic reactions [89]. 


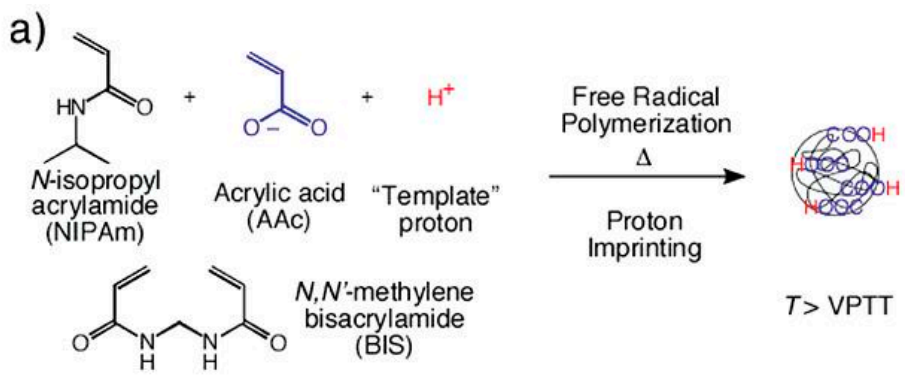

b)
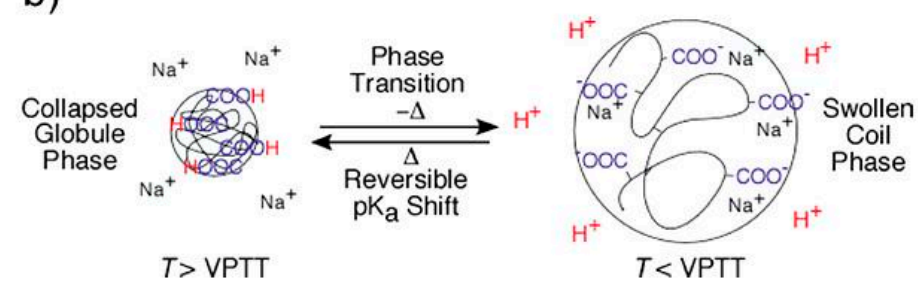

Figure 10. (a) Preparation of proton-imprinted NPs; (b) Reversible $\mathrm{p} K_{\mathrm{a}}$ shift of carboxylic acids in NPs triggered by the phase transition of NPs. Reprinted with permission from Reference 89. Copyright 2014, Wiley.

\section{Conclusions}

In this review, we give a short introduction to the development in stimuli-responsive MIPs, and it is obvious that stimuli-responsive MIPs will have important applications in separation, extraction, sensors, synthesized chemistry and biomedicine, etc. Up to now, various versatile approaches were developed to realize regulatory affinity in an imprinted network, but the approaches commonly displayed either advantages or disadvantages from different angles. Therefore, balancing the two aspects of the complex system is one of the most significant factors for outstanding responsive MIPs. In addition, new synthetic techniques, such as controlled radical polymerizations (CRPs), exhibit very fine control over polymer synthesis so that defined molecular weight, architecture, (co) monomer content and block distribution could be established in the imprinted network when the techniques were adopted for preparing responsive MIPs. This will lead to improved affinity as well as a well-defined responsibility, like a switch, due to homogeneous responsive blocks in the polymeric network in comparison with other radical polymerization. Furthermore, a variety of responsive blocks can be combined in one system step by step, affording truly multi-responsive MIPs for more extensive applications.

At present, despite the potential uses of responsive MIPs in biomedicine, the real applications in clinical trials are very rare. For example, temperature-responsive MIPs have drawn the greatest attention as temperature-induced phase transitions are perhaps the best understood in both theoretical and practical terms. However, the difficulties to achieve local temperature changes in vivo have limited their biomedical application. This is also the same problem for photo-responsive MIPs. However, MIPs that can respond to a specific biomolecule or ion are obviously of greater medical relevance. For example, sugar-responsive MIPs with insulin-binding affinity based on phenylboronic acid (a saccharide molecular receptor) $[116,117]$ will be a promising drug carrier candidate for diabetes therapy. Another problem is the biocompatibility of responsive MIPs. Although the suitable hydrophilic/hydrophobic equilibrium of the MIPs can be regulated elaborately, the toxicity of current material compositions, 
such as $N$-alkylacrylamide and azobenzene monomers, should be seriously considered. Excitingly, biopolymer such as natural thermo- and $\mathrm{pH}$-responsive polypeptides and biocompatible PEO and PPO block co-polymers such as pluronics, poloxamers and tetronics are available substituted candidates in vivo. Therefore, the development of responsive MIPs with biocompatible properties is a challenge that can be expected to yield a new generation of drug delivery devices, bioseparation devices, biosensors and tissue engineering materials for biomedical applications.

\section{Supplementary Information}

Supplementary materials can be accessed at: http://www.mdpi.com/2073-4360/7/9/1478/s1.

\section{Acknowledgments}

Guoqing Pan and Börje Sellergren acknowledge partial funding from Marie Skłodowska-Curie Fellowship (H2020-MSCA-IF-2014-EF, No. 658953) and the National Science Foundation of China (Grant Nos. 21574091, 21576120, and 21204056). Jianming Pan and Guoqing Pan also acknowledge the Special National Postdoctoral Science Foundation (No. 2014T70480, No. 2013T60555) and the Natural Science Foundation of Jiangsu Province (No. BK20131223, No. BK2012173).

\section{Author Contributions}

The manuscript was completed through contributions of all authors. Jianmin Pan, Guoqing Pan and Börje Sellergren initiated the topic and designed the entire content of this paper. Wei Chen and Yue Ma contributed to the writing of the paper. Zihui Meng, Jianmin Pan, Guoqing Pan and Börje Sellergren then disscussed and revised the paper. All authors have given approval to the final version of the manuscript.

\section{Conflicts of Interest}

The authors declare no conflict of interest.

\section{Abbreviations}

AA, Acrylic acid; AAm, Acrylic amide; AFP, $\alpha$-Fetoprotein; BPA, Bisphenol A; BSA, Bovine serum albumin; CFX, Cefalexin; Cyt C, Cytochrome C; DA, Dansylamide; DBTS, Dibenzothophene sulfone; DEDTC, $N, N$-diethyldithiocarbamate; DMAEMA, 2-(Dimethylamino)ethyl methacrylate; DMAPMA, $N$-(3-(dimethylamino)propyl)methacrylamide; DMF, Dimethyl formamide; DMSO, Dimethylsulfoxide; Dox, Doxorubicin; DVB, Divinylbenzene; EGDMA, Ethylene glycol dimethacrylate; HEMA, 2-Hydroxyethyl methacrylate; LCST, Low-critical solution temperature; Lys, Lysozyme; MAA, Methacrylic acid; MBAA, N,N-methylenebisacrylamide; MIPs, Molecularly imprinted polymers; MIH, Molecularly imprinted hydrogel; M-MIPs, Magnetic responsive MIPs; MPABA, 4-((4-Methacryloyloxy) phenylazo)benzoic acid; MAPASA, 4-((4-Methacryloyloxy)phenylazo) benzenesulfonic acid; MRS, Molecular recognition sites; QDs, Quantum dots; PCL-T, Polycaprolactone-triol; PCS, Photocatalytic sites; PEG, Poly(ethylene glycol); PES, Polyethersulfone; PhAAAn, $p$-phenylazoacrylanilide; NIPAAm, $N$-isopropylacrylamide; RAFT, Reversible addition-fragmentation chain transfer; RGDS, Arg-Gly-Asp-Se peptide; SRP, Stimuli 
responsive polymers; tBAm, N-tert-butylacrylamide; TRIM, Trimethylolpropane trimethacrylate; TTT, Tetramethacryloyl triethylene tetramine; VBIDA, $N$-(4-vinyl)-benzyl iminodiacetic; 4-HA, 4-Hydroxybenzoic acid; 4-VP, 4-Vinylpyridine.

\section{References}

1. Kirby, A.J. Enzyme mechanisms, models, and mimics. Angew. Chem. Int. Ed. Engl. 1996, 35, 706-724. [CrossRef]

2. Alexander, C.; Andersson, H.S.; Andersson, L.I.; Ansell, R.J.; Kirsch, N.; Nicholls, I.A.; O’Mahony, J.; Whitcombe, M.J. Molecular imprinting science and technology: A survey of the literature for the years up to and including 2003. J. Mol. Recognit. 2006, 19, 106-180. [CrossRef]

3. Whitcombe, M.J.; Kirsch, N.; Nicholls, I.A. Molecular imprinting science and technology: A survey of the literature for the years 2004-2011. J. Mol. Recognit. 2014, 27, 297-401. [CrossRef]

4. Haupt, K. Imprinted polymers-Tailor-made mimics of antibodies and receptors. Chem. Commun. 2003, 171-178. [CrossRef]

5. Haupt, K. Biomaterials: Plastic antibodies. Nat. Mater. 2010, 9, 612-614. [CrossRef]

6. Kawamura, A.; Kiguchi, T.; Nishihata, T.; Uragami, T.; Miyata, T. Target molecule-responsive hydrogels designed via molecular imprinting using bisphenol A as a template. Chem. Commun. 2014, 50, 11101-11103. [CrossRef]

7. Wu, B.; Peisley, A.; Tetrault, D.; Li, Z.; Egelman, E.H.; Magor, K.E.; Walz, T.; Penczek, P.A.; Hur, S. Molecular imprinting as a signal-activation mechanism of the viral RNA sensor RIG-I. Mol. Cell 2014, 55, 511-523. [CrossRef]

8. Emgenbroich, M.; Borrelli, C.; Shinde, S.; Lazraq, I.; Vilela, F.; Hall, A.J.; Oxelbark, J.; de Lorenzi, E.; Courtois, J.; Simanova, A. A phosphotyrosine-Imprinted polymer receptor for the recognition of tyrosine phosphorylated peptides. Chem. Eur. J. 2008, 14, 9516-9529. [CrossRef]

9. Zhang, H.; Ye, L.; Mosbach, K. Non-covalent molecular imprinting with emphasis on its application in separation and drug development. J. Mol. Recognit. 2006, 19, 248-259. [CrossRef]

10. Kyzas, G.Z.; Bikiaris, D.N. Molecular imprinting for high-added value metals: An overview of recent environmental applications. Adv. Mat. Sci. Eng. 2014, 2014, 932637. [CrossRef]

11. Rossetti, C.; Abdel Qader, A.; Halvorsen, T.G.; Sellergren, B.R.; Reubsaet, L. Antibody-free biomarker determination: Exploring molecularly imprinted polymers for pro-gastrin releasing peptide. Anal. Chem. 2014, 86, 12291-12298. [CrossRef]

12. Kunath, S.; Panagiotopoulou, M.; Maximilien, J.; Marchyk, N.; Sänger, J.; Haupt, K. Cell and tissue imaging with molecularly imprinted polymers as plastic antibody mimics. Adv. Healthcare Mat. 2015, 4, 1322-1326. [CrossRef]

13. Sellergren, B. Molecularly imprinted polymers: Shaping enzyme inhibitors. Nat. Chem. 2010, 2 , 7-8. [CrossRef]

14. Haupt, K.; Mosbach, K. Molecularly imprinted polymers and their use in biomimetic sensors. Chem. Rev. 2000, 100, 2495-2504. [CrossRef]

15. Wulff, G. Enzyme-like catalysis by molecularly imprinted polymers. Chem. Rev. 2002, 102, 1-28. [CrossRef] 
16. Omranipour, H.; Sajadi, T.S.; Kowsari, R.; Rad, M.; Mohajeri, S. Brimonidine imprinted hydrogels and evaluation of their binding and releasing properties as new ocular drug delivery systems. Curr. Drug Deliv. 2015. [CrossRef]

17. Hilt, J.Z.; Byrne, M.E. Configurational biomimesis in drug delivery: Molecular imprinting of biologically significant molecules. Adv. Drug Deliv. Rev. 2004, 56, 1599-1620. [CrossRef]

18. Komiyama, M.; Takeuchi, T.; Mukawa, T.; Asanuma, H. Molecular imprinting: From fundamentals to applications. Mol. Impr. 2003, 1, 148.

19. Krupadam, R.J.; Venkatesh, A.; Piletsky, S.A. Molecularly imprinted polymer receptors for nicotine recognition in biological systems. Mol. Impr. 2013, 1, 27-34. [CrossRef]

20. Alarcon, C.D.L.H.; Pennadam, S.; Alexander, C. Stimuli responsive polymers for biomedical applications. Chem. Soc. Rev. 2005, 34, 276-285. [CrossRef]

21. Stuart, M.A.C.; Huck, W.T.; Genzer, J.; Müller, M.; Ober, C.; Stamm, M.; Sukhorukov, G.B.; Szleifer, I.; Tsukruk, V.V.; Urban, M. Emerging applications of stimuli-responsive polymer materials. Nat. Mat. 2010, 9, 101-113. [CrossRef]

22. Ahn, S.-K.; Kasi, R.M.; Kim, S.-C.; Sharma, N.; Zhou, Y. Stimuli-responsive polymer gels. Soft Matter 2008, 4, 1151-1157. [CrossRef]

23. Ge, Y.; Butler, B.; Mirza, F.; Habib-Ullah, S.; Fei, D. Smart molecularly imprinted polymers: Recent developments and applications. Macromol. Rapid Commun. 2013, 34, 903-915. [CrossRef]

24. Pan, G.; Guo, Q.; Cao, C.; Yang, H.; Li, B. Thermo-responsive molecularly imprinted nanogels for specific recognition and controlled release of proteins. Soft Matter 2013, 9, 3840-3850. [CrossRef]

25. Zhang, Q.; Zhang, L.; Wang, P.; Du, S. Coordinate bonding strategy for molecularly imprinted hydrogels: Toward pH-responsive doxorubicin delivery. J. Pharm. Stat. 2014, 103, 643-651. [CrossRef]

26. Takeuchi, T.; Akeda, K.; Murakami, S.; Shinmori, H.; Inoue, S.; Lee, W.-S.; Hishiya, T. Photoresponsive porphyrin-imprinted polymers prepared using a novel functional monomer having diaminopyridine and azobenzene moieties. Org. Biomol. Chem. 2007, 5, 2368-2374. [CrossRef]

27. Wu, H.G.; Ju, X.J.; Xie, R.; Liu, Y.M.; Deng, J.G.; Niu, C.H.; Chu, L.Y. A novel ion-imprinted hydrogel for recognition of potassium ions with rapid response. Polym. Adv. Technol. 2011, 22, 1389-1394. [CrossRef]

28. Shiraki, Y.; Tsuruta, K.; Morimoto, J.; Ohba, C.; Kawamura, A.; Yoshida, R.; Kawano, R.; Uragami, T.; Miyata, T. Preparation of molecule-responsive microsized hydrogels via photopolymerization for smart microchannel microvalves. Macromol. Rapid Commun. 2015, 36, 515-519. [CrossRef]

29. Puoci, F.; Iemma, F.; Picci, N. Stimuli-responsive molecularly imprinted polymers for drug delivery: A review. Curr. Drug Deliv. 2008, 5, 85-96. [CrossRef]

30. Xu, S.; Lu, H.; Zheng, X.; Chen, L. Stimuli-responsive molecularly imprinted polymers: Versatile functional materials. J. Mater. Chem. C 2013, 1, 4406-4422. [CrossRef] 
31. Adrus, N.; Ulbricht, M. Molecularly imprinted stimuli-responsive hydrogels for protein recognition. Polymer 2012, 53, 4359-4366. [CrossRef]

32. Ying, X.; Qi, L.; Li, X.; Zhang, W.; Cheng, G. Stimuli-responsive recognition of BSA-imprinted poly vinyl acetate grafted calcium alginate core-shell hydrogel microspheres. J. Appl. Polym. Sci. 2013, 127, 3898-3909. [CrossRef]

33. Qin, L.; He, X.-W.; Yuan, X.; Li, W.-Y.; Zhang, Y.-K. Molecularly imprinted beads with double thermosensitive gates for selective recognition of proteins. Anal. Bioanal. Chem. 2011, 399, 3375-3385. [CrossRef]

34. Qin, L.; He, X.W.; Jia, M.; Li, W.Y.; Zhang, Y.K. A thermosensitive monolithic column as an artificial antibody for the on-line selective separation of the protein. Chem. Euro. J. 2011, 17, 1696-1704. [CrossRef]

35. Qin, L.; He, X.-W.; Zhang, W.; Li, W.-Y.; Zhang, Y.-K. Macroporous thermosensitive imprinted hydrogel for recognition of protein by metal coordinate interaction. Anal. Chem. 2009, 81, 7206-7216. [CrossRef]

36. Pan, G.; Zhang, Y.; Guo, X.; Li, C.; Zhang, H. An efficient approach to obtaining water-compatible and stimuli-responsive molecularly imprinted polymers by the facile surface-grafting of functional polymer brushes via RAFT polymerization. Biosens. Bioelectron. 2010, 26, 976-982. [CrossRef]

37. Pan, G.; Guo, Q.; Ma, Y.; Yang, H.; Li, B. Thermo-responsive hydrogel layers imprinted with RGDs peptide: A system for harvesting cell sheets. Angew. Chem. 2013, 125, 7045-7049. [CrossRef]

38. Ma, Y.; Zhang, Y.; Zhao, M.; Guo, X.; Zhang, H. Narrowly dispersed molecularly imprinted polymer microspheres with photo- and thermo-responsive template binding properties in pure aqueous media by RAFT polymerization. Mol. Impr. 2012, 1, 3-16. [CrossRef]

39. You, Q.; Zhang, Y.; Zhang, Q.; Guo, J.; Huang, W.; Shi, S.; Chen, X. High-capacity thermo-responsive magnetic molecularly imprinted polymers for selective extraction of curcuminoids. J. Chromatogr. A 2014, 1354, 1-8. [CrossRef]

40. Xu, L.; Pan, J.; Dai, J.; Li, X.; Hang, H.; Cao, Z.; Yan, Y. Preparation of thermal-responsive magnetic molecularly imprinted polymers for selective removal of antibiotics from aqueous solution. J. Hazard. Mater. 2012, 233, 48-56. [CrossRef]

41. Xu, Z.; Ding, L.; Long, Y.; Xu, L.; Wang, L.; Xu, C. Preparation and evaluation of superparamagnetic surface molecularly imprinted polymer nanoparticles for selective extraction of bisphenol A in packed food. Anal. Method. 2011, 3, 1737-1744. [CrossRef]

42. Pan, J.; Wang, B.; Dai, J.; Dai, X.; Hang, H.; Ou, H.; Yan, Y. Selective recognition of 2,4,5-trichlorophenol by temperature responsive and magnetic molecularly imprinted polymers based on halloysite nanotubes. J. Mater. Chem. 2012, 22, 3360-3369. [CrossRef]

43. Liu, X.; Zhou, T.; Du, Z.; Wei, Z.; Zhang, J. Recognition ability of temperature responsive molecularly imprinted polymer hydrogels. Soft Matter 2011, 7, 1986-1993. [CrossRef]

44. Tokuyama, H.; Kanazawa, R.; Sakohara, S. Equilibrium and kinetics for temperature swing adsorption of a target metal on molecular imprinted thermosensitive gel adsorbents. Sep. Purif. Technol. 2005, 44, 152-159. [CrossRef] 
45. Aburto, J.; Le Borgne, S. Selective adsorption of dibenzothiophene sulfone by an imprinted and stimuli-responsive chitosan hydrogel. Macromolecules 2004, 37, 2938-2943. [CrossRef]

46. Singh, B.; Chauhan, N.; Sharma, V. Design of molecular imprinted hydrogels for controlled release of cisplatin: Evaluation of network density of hydrogels. Ind. Eng. Chem. Res. 2011, 50, 13742-13751. [CrossRef]

47. Demirel, G.; Özçetin, G.; Turan, E.; Çaykara, T. pH/temperature-sensitive imprinted ionic poly ( $N$-tert-butylacrylamide-co-acrylamide/maleic acid) hydrogels for bovine serum albumin. Macromol. Biosci. 2005, 5, 1032-1037. [CrossRef]

48. Ran, D.; Wang, Y.; Jia, X.; Nie, C. Bovine serum albumin recognition via thermosensitive molecular imprinted macroporous hydrogels prepared at two different temperatures. Anal. Chim. Acta 2012, 723, 45-53. [CrossRef]

49. Miyata, T.; Jige, M.; Nakaminami, T.; Uragami, T. Tumor marker-responsive behavior of gels prepared by biomolecular imprinting. Proc. Natl. Acad. Sci. USA 2006, 103, 1190-1193. [CrossRef]

50. Alvarez-Lorenzo, C.; Guney, O.; Oya, T.; Sakai, Y.; Kobayashi, M.; Enoki, T.; Takeoka, Y.; Ishibashi, T.; Kuroda, K.; Tanaka, K. Reversible adsorption of calcium ions by imprinted temperature sensitive gels. J. Chem. Phys. 2001, 114, 2812-2816. [CrossRef]

51. Wang, C.; Howell, M.; Raulji, P.; Davis, Y.; Mohapatra, S. Preparation and characterization of molecularly imprinted polymeric nanoparticles for atrial natriuretic peptide (ANP). Adv. Funct. Mater. 2011, 21, 4423-4429. [CrossRef]

52. Chen, Z.; Hua, Z.; Xu, L.; Huang, Y.; Zhao, M.; Li, Y. Protein-responsive imprinted polymers with specific shrinking and rebinding. J. Mol. Recognit. 2008, 21, 71-77. [CrossRef]

53. Li, S.; Pilla, S.; Gong, S. Modulated molecular recognition by a temperature-sensitive molecularly-imprinted polymer. J. Polym. Sci. Part A Polym. Chem. 2009, 47, 2352-2360. [CrossRef]

54. Li, S.; Ge, Y.; Tiwari, A.; Wang, S.; Turner, A.P.; Piletsky, S.A. "On/off”-switchable catalysis by a smart enzyme-like imprinted polymer. J. Catal. 2011, 278, 173-180. [CrossRef]

55. Zhang, W.; He, X.-W.; Li, W.-Y.; Zhang, Y.-K. Thermo-sensitive imprinted polymer coating CdTe quantum dots for target protein specific recognition. Chem. Commun. 2012, 48, 1757-1759. [CrossRef]

56. Xu, L.; Pan, J.; Xia, Q.; Shi, F.; Dai, J.; Wei, X.; Yan, Y. Composites of silica and molecularly imprinted polymers for degradation of sulfadiazine. J. Phys. Chem. C 2012, 116, 25309-25318. [CrossRef]

57. Suedee, R.; Seechamnanturakit, V.; Canyuk, B.; Ovatlarnporn, C.; Martin, G.P. Temperature sensitive dopamine-imprinted ( $N, N$-methylene-bis-acrylamide cross-linked) polymer and its potential application to the selective extraction of adrenergic drugs from urine. J. Chromatogr. A 2006, 1114, 239-249. [CrossRef]

58. Ma, Y.; Zhang, Y.; Zhao, M.; Guo, X.; Zhang, H. Efficient synthesis of narrowly dispersed molecularly imprinted polymer microspheres with multiple stimuli-responsive template binding properties in aqueous media. Chem. Commun. 2012, 48, 6217-6219. [CrossRef] 
59. Wang, C.; Javadi, A.; Ghaffari, M.; Gong, S. A pH-sensitive molecularly imprinted nanospheres/hydrogel composite as a coating for implantable biosensors. Biomaterials 2010, 31 , 4944-4951. [CrossRef]

60. Suedee, R.; Jantarat, C.; Lindner, W.; Viernstein, H.; Songkro, S.; Srichana, T. Development of a $\mathrm{pH}$-responsive drug delivery system for enantioselective-controlled delivery of racemic drugs. J. Control. Release 2010, 142, 122-131. [CrossRef]

61. Kanekiyo, Y.; Naganawa, R.; Tao, H. pH-Responsive molecularly imprinted polymers. Angew. Chem. Int. Ed. 2003, 42, 3014-3016. [CrossRef]

62. Zhao, W.; Fang, B.; Li, N.; Nie, S.; Wei, Q.; Zhao, C. Fabrication of pH-responsive molecularly imprinted polyethersulfone particles for bisphenol-A uptake. J. Appl. Polym.Sci. 2009, 113, 916-921. [CrossRef]

63. Griffete, N.; Frederich, H.; Maître, A.S.; Ravaine, S.; Chehimi, M.M.; Mangeney, C. Inverse opals of molecularly imprinted hydrogels for the detection of bisphenol $\mathrm{A}$ and $\mathrm{pH}$ sensing. Langmuir 2011, 28, 1005-1012. [CrossRef]

64. Chen, Z.; Xu, L.; Liang, Y.; Zhao, M. pH-sensitive water-soluble nanospheric imprinted hydrogels prepared as horseradish peroxidase mimetic enzymes. Adv. Mater. 2010, 22, 1488-1492. [CrossRef]

65. Mohajeri, S.A.; Malaekeh-Nikouei, B.; Sadegh, H. Development of a pH-responsive imprinted polymer for diclofenac and study of its binding properties in organic and aqueous media. Drug Dev. Ind. Pharm. 2012, 38, 616-622. [CrossRef]

66. Li, S.; Tiwari, A.; Ge, Y.; Fei, D. A pH-responsive, low crosslinked, molecularly imprinted insulin delivery system. Adv. Mater. Lett. 2010, 1, 4-10. [CrossRef]

67. Gong, C.; Lam, M.W.; Yu, H. The fabrication of a photoresponsive molecularly imprinted polymer for the photoregulated uptake and release of caffeine. Adv. Funct. Mater. 2006, 16, 1759-1767. [CrossRef]

68. Gomy, C.; Schmitzer, A.R. Synthesis and photoresponsive properties of a molecularly imprinted polymer. Org. Lett. 2007, 9, 3865-3868. [CrossRef]

69. Xu, S.; Li, J.; Song, X.; Liu, J.; Lu, H.; Chen, L. Photonic and magnetic dual responsive molecularly imprinted polymers: Preparation, recognition characteristics and properties as a novel sorbent for caffeine in complicated samples. Anal. Method. 2013, 5, 124-133. [CrossRef]

70. Gong, C.; Wong, K.-L.; Lam, M.H. Photoresponsive molecularly imprinted hydrogels for the photoregulated release and uptake of pharmaceuticals in the aqueous media. Chem. Mater. 2008, 20, 1353-1358. [CrossRef]

71. Tang, Q.; Nie, Y.-T.; Gong, C.-B.; Chow, C.-F.; Peng, J.-D.; Lam, M.H.-W. Photo-responsive molecularly imprinted hydrogels for the detection of melamine in aqueous media. J. Mater. Chem. 2012, 22, 19812-19820. [CrossRef]

72. Gong, C.-B.; Yang, Y.-Z.; Gao, C.; Tang, Q.; Chow, C.-F.; Peng, J.-D.; Lam, M.H.-W. The preparation and characterization of photo-responsive sol-gel materials for 2,4-dichlorophenoxyacetic acid by surface imprinting. J. Sol-Gel Sci. Technol. 2013, 67, 442-450. [CrossRef] 
73. Fang, L.; Chen, S.; Guo, X.; Zhang, Y.; Zhang, H. Azobenzene-containing molecularly imprinted polymer microspheres with photo- and thermoresponsive template binding properties in pure aqueous media by atom transfer radical polymerization. Langmuir 2012, 28, 9767-9777. [CrossRef]

74. Fang, L.; Chen, S.; Zhang, Y.; Zhang, H. Azobenzene-containing molecularly imprinted polymer microspheres with photoresponsive template binding properties. J. Mater. Chem. 2011, 21, 2320-2329. [CrossRef]

75. Jiang, G.S.; Zhong, S.A.; Chen, L.; Blakey, I.; Whitaker, A. Synthesis of molecularly imprinted organic-inorganic hybrid azobenzene materials by sol-gel for radiation induced selective recognition of 2, 4-dichlorophenoxyacetic acid. Radiat. Phys. Chem. 2011, 80, 130-135. [CrossRef]

76. Wang, D.; Zhang, X.; Nie, S.; Zhao, W.; Lu, Y.; Sun, S.; Zhao, C. Photoresponsive surface molecularly imprinted poly(ether sulfone) microfibers. Langmuir 2012, 28, 13284-13293. [CrossRef]

77. Li, C.-E.; Zhong, S.-A.; Li, X.-J.; Guo, M. Silica particles coated with azobenzene-containing photoresponsive molecule-imprinted skin layer. Colloid. Polym. Sci. 2013, 291, 2049-2059. [CrossRef]

78. Tang, Q.; Gong, C.; Lam, M.H.-W.; Fu, X. Photoregulated uptake and release of drug by an organic-inorganic hybrid sol-gel material. J. Sol-Gel Sci. Technol. 2011, 59, 495-504. [CrossRef]

79. Li, Z.-Y.; Quan, H.-J.; Gong, C.-B.; Yang, Y.-Z.; Tang, Q.; Wei, Y.-B.; Ma, X.-B.; Lam, H.-W. Photocontrolled solid-phase extraction of guanine from complex samples using a novel photoresponsive molecularly imprinted polymer. Food Chem. 2015, 172, 56-62. [CrossRef]

80. Tang, Q.; Gong, C.; Lam, M.H.W.; Fu, X. Preparation of a photoresponsive molecularly imprinted polymer containing fluorine-substituted azobenzene chromophores. Sens. Actuators B 2011, 156, 100-107. [CrossRef]

81. Yang, Y.-Z.; Tang, Q.; Gong, C.-B.; Ma, X.-B.; Peng, J.-D.; Lam, M.H.-W. Ultrasensitive detection of bisphenol $\mathrm{A}$ in aqueous media using photoresponsive surface molecular imprinting polymer microspheres. New J. Chem. 2014, 38, 1780-1788. [CrossRef]

82. Minoura, N.; Idei, K.; Rachkov, A.; Choi, Y.-W.; Ogiso, M.; Matsuda, K. Preparation of azobenzene-containing polymer membranes that function in photoregulated molecular recognition. Macromolecules 2004, 37, 9571-9576. [CrossRef]

83. Minoura, N.; Idei, K.; Rachkov, A.; Uzawa, H.; Matsuda, K. Molecularly imprinted polymer membranes with photoregulated template binding. Chem. Mater. 2003, 15, 4703-4704. [CrossRef]

84. Sreenivasan, K. On the application of molecularly imprinted poly (HEMA) as a template responsive release system. J. Appl. Polym. Sci. 1999, 71, 1819-1821. [CrossRef]

85. Miyata, T.; Jige, M.; Hishida, Y.; Okawa, K.; Ohya, Y.; Ouchi, T.; Uragami, T. Preparation of Biomolecule-Responsive Gels by Biomolecular Imprinting. In Proceedings of the AIChE Annual Meeting, San Francisco, CA, USA, 12-17 November 2006. 
86. Bai, W.; Gariano, N.A.; Spivak, D.A. Macromolecular amplification of binding response in superaptamer hydrogels. J. Am. Chem. Soc. 2013, 135, 6977-6984. [CrossRef]

87. Watanabe, M.; Akahoshi, T.; Tabata, Y.; Nakayama, D. Molecular specific swelling change of hydrogels in accordance with the concentration of guest molecules. J. Am. Chem. Soc. 1998, 120, 5577-5578. [CrossRef]

88. Hua, Z.; Chen, Z.; Li, Y.; Zhao, M. Thermosensitive and salt-sensitive molecularly imprinted hydrogel for bovine serum albumin. Langmuir 2008, 24, 5773-5780. [CrossRef]

89. Hoshino, Y.; Ohashi, R.C.; Miura, Y. Rational design of synthetic nanoparticles with a large reversible shift of acid dissociation constants: Proton imprinting in stimuli responsive nanogel particles. Adv. Mater. 2014, 26, 3718-3723. [CrossRef]

90. Laidler, K.J.; Peterman, B.F. [10] Temperature effects in enzyme kinetics. Methods Enzymol. 1979, 63, 234-257.

91. Schild, H.G. Poly ( $N$-isopropylacrylamide): Experiment, theory and application. Prog. Polym. Sci. 1992, 17, 163-249. [CrossRef]

92. Plunkett, K.N.; Zhu, X.; Moore, J.S.; Leckband, D.E. PNIPAM chain collapse depends on the molecular weight and grafting density. Langmuir 2006, 22, 4259-4266. [CrossRef]

93. Nash, M.E.; Fan, X.; Carroll, W.M.; Gorelov, A.V.; Barry, F.P.; Shaw, G.; Rochev, Y.A. Thermoresponsive substrates used for the expansion of human mesenchymal stem cells and the preservation of immunophenotype. Stem Cell Rev. Rep. 2013, 9, 148-157. [CrossRef]

94. Oya, T.; Enoki, T.; Grosberg, A.Y.; Masamune, S.; Sakiyama, T.; Takeoka, Y.; Tanaka, K.; Wang, G.; Yilmaz, Y.; Feld, M.S. Reversible molecular adsorption based on multiple-point interaction by shrinkable gels. Science 1999, 286, 1543-1545. [CrossRef]

95. D’Oleo, R.; Alvarez-Lorenzo, C.; Sun, G. A new approach to design imprinted polymer gels without using a template. Macromolecules 2001, 34, 4965-4971. [CrossRef]

96. Ozmen, M.M.; Okay, O. Swelling behavior of strong polyelectrolyte poly ( $N$-t-butylacrylamide-co-acrylamide) hydrogels. Eur. Polym. J. 2003, 39, 877-886. [CrossRef]

97. Lovett, J.R.; Warren, N.J.; Ratcliffe, L.P.; Kocik, M.K.; Armes, S.P. pH-responsive non-ionic diblock copolymers: Ionization of carboxylic acid end-groups induces an order-order morphological transition. Angew. Chem. Int. Ed. 2015, 54, 1279-1283. [CrossRef]

98. Némethy, Á.; Solti, K.; Kiss, L.; Gyarmati, B.; Deli, M.A.; Csányi, E.; Szilágyi, A. pH-and temperature-responsive poly (aspartic acid)-L-poly( $N$-isopropylacrylamide) conetwork hydrogel. Eur. Polym. J. 2013, 49, 2392-2403.

99. Begum, G.; Laxmi, M.V.; Rana, R.K. Entrapped polyamines in biomimetically synthesized nanostructured silica spheres as $\mathrm{pH}$-responsive gates for controlled drug release. J. Mater. Chem. 2012, 22, 22174-22180. [CrossRef]

100. Kanekiyo, Y.; Tao, H.; Sellergren, B. Stimuli-responsive guest binding and releasing by dendritic polymer-based hydrogels. Polym. J. 2008, 40, 684-687. [CrossRef]

101. Puoci, F.; Cirillo, G.; Curcio, M.; Parisi, O.I.; Iemma, F.; Picci, N. Molecularly imprinted polymers in drug delivery: State of art and future perspectives. Expert Opin. Drug Deliv. 2011, 8, 1379-1393. [CrossRef] 
102. Puoci, F.; Iemma, F.; Cirillo, G.; Curcio, M.; Parisi, O.I.; Spizzirri, U.G.; Picci, N. New restricted access materials combined to molecularly imprinted polymers for selective recognition/release in water media. Eur. Polym. J. 2009, 45, 1634-1640. [CrossRef]

103. Kanekiyo, Y.; Naganawa, R.; Tao, H. Molecular imprinting of bisphenol A and alkylphenols using amylose as a host matrix. Chem. Commun. 2002, 22, 2698-2699. [CrossRef]

104. Oral, E.; Peppas, N.A. Responsive and recognitive hydrogels using star polymers. J. Biomed. Mater. Res. Part A 2004, 68, 439-447. [CrossRef]

105. Zhao, K.; Cheng, G.; Wei, J.; Zhou, J.; Zhang, J.; Chen, L. The rebinding properties of bovine serum albumin imprinted calcium alginate/phosphate hybrid microspheres via the adjustment of pH values and salt concentration. Macromol. Symp. 2010, 297, 126-137. [CrossRef]

106. Kumar, G.S.; Neckers, D. Photochemistry of azobenzene-containing polymers. Chem. Rev. 1989, 89, 1915-1925. [CrossRef]

107. Waldeck, D.H. Photoisomerization dynamics of stilbenes. Chem. Rev. 1991, 91, 415-436. [CrossRef]

108. Berkovic, G.; Krongauz, V.; Weiss, V. Spiropyrans and spirooxazines for memories and switches. Chem. Rev. 2000, 100, 1741-1754. [CrossRef]

109. Yokoyama, Y. Fulgides for memories and switches. Chem. Rev. 2000, 100, 1717-1740. [CrossRef]

110. Asano, T.; Okada, T. Thermal ZE isomerization of azobenzenes. The pressure, solvent, and substituent effects. J. Org. Chem. 1984, 49, 4387-4391. [CrossRef]

111. Siampiringue, N.; Guyot, G.; Monti, S.; Bortolus, P. The $c i s \rightarrow$ trans photoisomerization of azobenzene: An experimental re-examination. J. Photochem. 1987, 37, 185-188. [CrossRef]

112. Hermann, D.; Rudquist, P.; Ichimura, K.; Kudo, K.; Komitov, L.; Lagerwall, S. Flexoelectric polarization changes induced by light in a nematic liquid crystal. Phys. Rev. E 1997, 55, 2857. [CrossRef]

113. Ye, L.; Cormack, P.A.; Mosbach, K. Molecularly imprinted monodisperse microspheres for competitive radioassay. Anal. Commun. 1999, 36, 35-38. [CrossRef]

114. Shimoboji, T.; Larenas, E.; Fowler, T.; Kulkarni, S.; Hoffman, A.S.; Stayton, P.S. Photoresponsive polymer-enzyme switches. Proc. Natl. Acad. Sci. USA 2002, 99, 16592-16596. [CrossRef]

115. Chu, L.Y.; Yamaguchi, T.; Nakao, S.-I. A molecular-recognition microcapsule for environmental stimuli-responsive controlled release. Adv. Mater. 2002, 14, 386-389. [CrossRef]

116. Pan, G.; Guo, B.; Ma, Y.; Cui, W.; He, F.; Li, B.; Yang, H.; Shea, K.J. Dynamic introduction of cell adhesive factor via reversible multicovalent phenylboronic acid/cis-diol polymeric complexes. J. Am. Chem. Soc. 2014, 136, 6203-6206. [CrossRef]

117. Guo, B.; Pan, G.; Guo, Q.; Zhu, C.; Cui, W.; Li, B.; Yang, H. Saccharides and temperature dual-responsive hydrogel layers for harvesting cell sheets. Chem. Commun. 2015, 51, 644-647. [CrossRef]

(C) 2015 by the authors; licensee MDPI, Basel, Switzerland. This article is an open access article distributed under the terms and conditions of the Creative Commons Attribution license (http://creativecommons.org/licenses/by/4.0/). 